Atmos. Chem. Phys., 14, 4013-4027, 2014

www.atmos-chem-phys.net/14/4013/2014/

doi:10.5194/acp-14-4013-2014

(c) Author(s) 2014. CC Attribution 3.0 License.

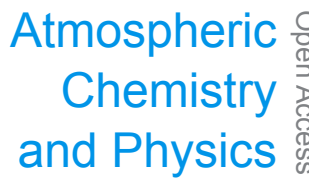

\title{
Simulation of aromatic SOA formation using the lumping model integrated with explicit gas-phase kinetic mechanisms and aerosol-phase reactions
}

\author{
Y. Im, M. Jang, and R. L. Beardsley \\ Department of Environmental Engineering Sciences, University of Florida, P.O. Box 116450, Gainesville, FL 32611, USA \\ Correspondence to: M. Jang (mjang@ufl.edu)
}

Received: 18 December 2012 - Published in Atmos. Chem. Phys. Discuss.: 6 March 2013

Revised: 1 March 2014 - Accepted: 3 March 2014 - Published: 23 April 2014

\begin{abstract}
The Unified Partitioning-Aerosol phase Reaction (UNIPAR) model has been developed to predict the secondary organic aerosol (SOA) formation through multiphase reactions. The model was evaluated with aromatic SOA data produced from the photooxidation of toluene and 1,3,5trimethylbenzene (135-TMB) under various concentrations of $\mathrm{NO}_{\mathrm{x}}$ and $\mathrm{SO}_{2}$ using an outdoor reactor (University of Florida Atmospheric PHotochemical Outdoor Reactor (UFAPHOR) chamber). When inorganic species (sulfate, ammonium and water) are present in aerosol, the prediction of both toluene SOA and 135-TMB SOA, in which the oxygen-tocarbon $(\mathrm{O}: \mathrm{C})$ ratio is lower than 0.62 , are approached under the assumption of a complete organic/electrolyte-phase separation below a certain relative humidity. An explicit gaskinetic model was employed to express gas-phase oxidation of aromatic hydrocarbons. Gas-phase products are grouped based on their volatility (6 levels) and reactivity (5 levels) and exploited to construct the stoichiometric coefficient $\left(\alpha_{i, j}\right)$ matrix, the set of parameters used to describe the concentrations of organic compounds in multiphase. Weighting of the $\alpha_{i, j}$ matrix as a function of $\mathrm{NO}_{\mathrm{x}}$ improved the evaluation of $\mathrm{NO}_{\mathrm{x}}$ effects on aromatic SOA. The total amount of organic matter $\left(\mathrm{OM}_{\mathrm{T}}\right)$ is predicted by two modules in the UNIPAR model: $\mathrm{OM}_{\mathrm{P}}$ by a partitioning process and $\mathrm{OM}_{\mathrm{AR}}$ by aerosol-phase reactions. The $\mathrm{OM}_{\mathrm{AR}}$ module predicts multiphase reactions of organic compounds, such as oligomerization, acid-catalyzed reactions, and organosulfate (OS) formation. The model reasonably simulates SOA formation under various aerosol acidities, $\mathrm{NO}_{\mathrm{x}}$ concentrations, humidities and temperatures. Furthermore, the OS fractions in the SOA pre-
\end{abstract}

dicted by the model were in good agreement with the experimentally measured OS fractions.

\section{Introduction}

Organic aerosols have attracted the interest of many researchers because of the significant role they play in climate forcing (IPCC, 2001), human health (Schwartz et al., 1996), and visibility (Bäumer et al., 2008). The oxidation of reactive volatile organic hydrocarbons (VOCs) produces semivolatile multifunctional products that can form secondary organic aerosols (SOA) through either gas-particle partitioning or aerosol-phase reactions. Although SOA makes up a major fraction of atmospheric aerosol, the development of a model to predict the formation of SOA remains difficult, due to the complexity of formation mechanisms in both the gas and aerosol phases as well as the diversity of compounds (a large fraction of which remain unidentified).

The gas-particle partitioning of semivolatile organic compounds is an important source of SOA. The complex task of predicting SOA formation was facilitated by the gas-particle partitioning model, which uses several semivolatile surrogate products (e.g., two products) (Odum et al., 1996) with semiempirical parameters (mass-based stoichiometric coefficient and gas-particle partitioning coefficient) for a given aerosol system. Donahue et al. (2006) have further advanced SOA modeling through the volatility basis set (VBS) approach. In their model, the volatility distribution of products is represented using a group of volatility bins, and the multigenerational oxidation of the products is illustrated by remapping their effective saturation concentrations in the volatility 
bins using a transformation matrix. Subsequently, Cappa and Willson (2012) have simulated SOA mass and bulk aerosol oxygen : carbon $(\mathrm{O}: \mathrm{C})$ atomic ratios employing tunable parameters to describe the kinetic evolution of SOA mass associated with precursor VOC oxidation and further photochemical aging of gas-phase products. There have also been some models that have integrated explicit gas-phase kinetic mechanisms of VOC oxidation with gas-particle partitioning. For example, Kamens et al. (1999) predicted the SOA formation by kinetically representing the gas-particle partitioning process of semivolatile organic compounds (SVOCs) using the rate constants of condensation and evaporation in the gaskinetic mechanism.

Although recent efforts advanced the prediction of SOA formation, partitioning-based SOA models remain incomplete and inaccurate. For example, the physical state (Zuend and Seinfeld, 2012) and water content of aerosols as well as complex aerosol-phase chemistry via the interaction between organic and inorganic compounds all influence SOA formation and likely require treatment by a multiphase SOA model. It has been known that aerosol-phase chemistry can significantly increase SOA mass, forming nonvolatile high molecular weight (MW) oligomers. Many studies have recently reported that SOA formation is accelerated by acidcatalyzed reactions (e.g., hydration, polymerization, formation of hemiacetal/acetal/trioxane, aldol condensation, and cationic rearrangement) (Jang and Kamens, 2001; Garland et al., 2006) in the presence of inorganic aerosol for both the oxidation products of biogenic (Czoschke et al., 2003; Iinuma et al., 2004; Kleindienst et al., 2006; Surratt et al., 2007) and aromatic hydrocarbons (Cao and Jang, 2007, 2010). However, there are noted discrepancies among field studies on the effect of aerosol acidity on SOA production (Zhang et al., 2007; Peltier et al., 2007). When humidity is high, the effect of acid-catalyzed reactions on SOA yields becomes indistinct since the reactions of organic compounds in the aqueous phase can considerably contribute to SOA formation (Czoschke and Jang, 2006). Furthermore, it also has been found that a new class of products, organosulfates (OS), can be formed through the aerosol-phase reaction of organic species with sulfate, bisulfate (Liggio et al., 2005; Betterton and Hoffmann, 1987) or their radicals (Galloway et al., 2009; Olson et al., 2011; Darer et al., 2011). As OS forms, the effect of acid-catalyzed reactions on SOA yields becomes less apparent due to the consumption of sulfuric acid (SA) and the reduction of the amount of water in aerosol.

Both laboratory and modeling studies (Clegg et al., 2001; Chang and Pankow, 2006; Ciobanu et al., 2009; Bertram et al., 2011; Song et al., 2012; Zuend and Seinfeld, 2012) have suggested the importance of the consideration of a liquid-liquid phase separation (LLPS) between the organic and electrolyte aqueous phases for an accurate modeling of organic aerosol mass. In the recent studies using an aerosol mass spectrometer, the chemical compositions of SOAs have been expressed using $\mathrm{O}: \mathrm{C}$ ratios and organic : sulfate ratios
(Sato et al., 2012; Loza et al., 2012). For example, Nakao et al. (2011) have shown that the $\mathrm{O}: \mathrm{C}$ ratios of toluene SOA $\left(\mathrm{H}_{2} \mathrm{O}_{2}\right)$ approached 0.65 and those of $m$-xylene peaked at 0.45 . Sato et al. (2012) have reported that $\mathrm{O}: \mathrm{C}$ ratios ranged $0.35-0.57$ for 1,3,5-trimethylbenzene (135-TMB-) $\mathrm{NO}_{\mathrm{x}} \mathrm{SOA}$ and $0.59-0.65$ for toluene- $\mathrm{NO}_{\mathrm{x}} \mathrm{SOA}$. Kuwata et al. (2013) reported that $\mathrm{O}: \mathrm{C}$ ratios ranged $0.38-0.48$ for ozone- $\alpha$ pinene SOA and $0.69-0.72$ for ozone-isoprene SOA. It has been shown that the relative humidity $(\mathrm{RH})$ at which organic/electrolyte-phase separation occurs can be feasibly determined using measured SOA O : $\mathrm{C}$ ratios (Bertram et al., 2011). Furthermore, Zuend and Seinfeld (2012) have applied the inorganic thermodynamic model to the ozone- $\alpha$-pinene $\mathrm{SOA} / \mathrm{ammonium}$ sulfate $(\mathrm{AS})$ particle system $(\mathrm{O}: \mathrm{C}$ ratio is lower than 0.6) with different assumptions for aerosol-phase separation and mixing state (ideal vs nonideal). They showed that SOA yields were reasonably predicted when complete LLPS was applied to the ozone- $\alpha$-pinene SOA/AS particle under ambient RH.

In the present study, the Unified Partitioning-Aerosol phase Reaction (UNIPAR) model was advanced in order to predict the SOA formation through multiphase reactions. The model was evaluated using outdoor chamber data for the SOA produced from the photooxidation of toluene or $135-\mathrm{TMB}$ in the presence and absence of $\mathrm{SO}_{2}$ under varying $\mathrm{NO}_{\mathrm{x}}$ conditions. In the presence of inorganic species (sulfate, ammonium and water), SOA formation of both aromatic species was approached assuming complete organic/electrolyte-phase separation below a certain $\mathrm{RH}(\leq 65 \%$ during aromatic photooxidation) since the reported $\mathrm{O}: \mathrm{C}$ ratios of both aromatic SOAs are relatively small $(\sim 0.62)$. The UNIPAR model of this study has revised the previous model by Gang and Jang (2010) to allow for simulation of SOA formation under dynamically changing atmospheric conditions $\left(\mathrm{NO}_{\mathrm{x}}\right.$, temperature, humidity, sunlight and particle acidity). The UNIPAR model provides flexibility for volatility and aerosol reactivity of various oxygenated products expressed with 30 lumping groups. The SOA mass is also predicted via recently discovered aerosol-phase chemistry, such as the oligomerization in both organic and inorganic phases, acid-catalyzed reactions and the formation of OS. In terms of the expression of aerosol chemistry, the dynamic change of aerosol acidity (e.g., ammonia titration of acidic aerosol and acidity change by OS formation) has been improved.

\section{Experimental section}

SOA formation from the photooxidation of aromatic volatile organic compounds (AVOCs) (i.e., toluene or 135-TMB) with and without $\mathrm{SO}_{2}$ under two different $\mathrm{NO}_{\mathrm{x}}$ conditions was studied using the University of Florida Atmospheric PHotochemical Outdoor Reactor (UF-APHOR) dual chambers located on the roof of Black Hall $\left(29.64185^{\circ}\right.$, 
$-82.347883^{\circ}$ ) at the University of Florida, Gainesville, Florida. The air volume of the half-cylinder-shaped, dual chambers is $104 \mathrm{~m}^{3}\left(52 \mathrm{~m}^{3}+52 \mathrm{~m}^{3}\right)$ (Fig. S1). The dual, Teflon film chambers allow for two experiments to be conducted simultaneously under the same meteorological conditions, e.g., sunlight, temperature and RH. A detailed description of the chamber, experimental procedures, and instrumentation is shown in the Supplement (Sect. S1).

SOA mass was determined by measuring the organic carbon (OC) concentration (semicontinuous OC/EC (elemental carbon) aerosol analyzer, Sunset Laboratory, Model 4). The $\mathrm{OC}$ is converted to organic matter $(\mathrm{OM})$ by multiplying by the $[\mathrm{OM}] /[\mathrm{OC}]$ ratio $(2.0)$, which is the reported value for aromatic SOA (Izumi and Fukuyama, 1990; Kleindienst et al., 2007). The SOA yield $(Y)$ is calculated as the ratio of the formed $\mathrm{OM}$ to the reacted hydrocarbon concentration ( $\Delta \mathrm{HC}): Y=\Delta \mathrm{OM} / \Delta \mathrm{HC}$ (Odum et al., 1996). The proton concentration $\left(\left[\mathrm{H}^{+}\right], \mathrm{mol} \mathrm{L}^{-1}\right.$ in the inorganic aerosol) was measured by two methods: particle-into-liquid samplerion chromatography (PILS-IC) with the inorganic thermodynamic model (E-AIM II) (Clegg et al., 2001) and the colorimetry integrated with a Reflectance UV-visible Spectrometer (C-RUV) method (Jang et al., 2008). A detailed description of the acidity measurement using the C-RUV method is shown in the Supplement (Sect. $\mathrm{S} 1)$. The $\left[\mathrm{H}^{+}\right]$estimated from PILS-IC data does not include the acidity change by OS formation, while that from C-RUV data includes OS formation. Therefore, the difference in $\left[\mathrm{H}^{+}\right]$between two methods is used to estimate OS (a detailed calculation of OS is described in Sect. 3.5).

\section{Description of the UNIPAR model}

In the presence of inorganic species (ammonium, sulfate and water), both toluene SOA and 135-TMB SOA are assumed to have two completely separated phases (an organic phase and inorganic aqueous phase). In a recent study by Bertram et al. (2011), the LLPS of organic/ammonium sulfate particles has been parameterized using model organic compounds as a function of the elemental $\mathrm{O}: \mathrm{C}$ ratio and organic : sulfate ratio. Based on the previously reported $\mathrm{O}: \mathrm{C}$ ratios of toluene SOA (0.62 on average) (Sato et al., 2012) and our measured organic : sulfate ratio (ranging 1-6), the predicted RH value for the LLPS of toluene SOA is about $65 \%$. Similarly, based on the reported O :C ratio of 135-TMB SOA ( 0.46 on average) (Sato et al., 2012), the predicted RH at LLPS for 135TMB SOA is expected to be higher than $90 \%$. Thus, the assumption of phase separation for the two aromatic SOA is justified as the chamber experiments are largely conducted at RH below their respective LLPS RH values. The humidity conditions during chamber experiments were lower than $65 \%$, except for a short period at the beginning of each experiment, and SOA formation is negligible at this time (less than $1 \mathrm{~h}$ ). Furthermore, the solubility of oligomeric products in water is generally much less than those of monomers. Thus, the actual RH at LLPS in aerosol is more likely to be greater than predicted RH at LLPS.

Figure 1 illustrates how major processes in both the gas and aerosol phases are connected to SOA formation. Overall, the UNIPAR model is operated as followed.

1. Gas-phase chemistry is treated by the Master Chemical Mechanism (MCM V3.2) (Jenkin et al., 2003; Bloss et al., 2005), an explicit gas-phase kinetic mechanism, and provides the concentrations and chemical structures (functional groups) of oxidized products in the gas phase (Sect. 3.1).

2. To effectively account for wide ranges of complex atmospheric oxidized products, the model employs a lumping frame based on the volatility of the chemical species and the reactivity in aerosol-phase reactions. Weighting of the lumping matrix as a function of $\mathrm{NO}_{\mathrm{x}}$ improved the evaluation of $\mathrm{NO}_{\mathrm{x}}$ effects on SOA (Sect. 3.2).

3. With the assumption of complete organic/electrolytephase separation, the aerosol-phase concentrations of each lumping group are dynamically estimated by a thermodynamic model (partitioning of lumping species between the gas ( $\mathrm{g}$ ), organic aerosol (or) and inorganic aerosol (in) phases) (Sect. 3.3)

4. The total organic matter $\left(\mathrm{OM}_{\mathrm{T}}\right)$, or SOA mass, in the UNIPAR model is predicted by two modules: the module for organic matter $\left(\mathrm{OM}_{\mathrm{P}}\right)$ by a partitioning process and the module for the $\mathrm{OM}\left(\mathrm{OM}_{\mathrm{AR}}\right)$ produced by aerosol-phase reactions of organic compounds (Sects. 3.4-3.6).

5. $\mathrm{OM}_{\mathrm{AR}}$ includes oligomerization, acid-catalyzed reactions, and OS formation (Sect. 3.4). In order to express aerosol chemistry, aerosol acidity is dynamically determined via the estimation of both ammonia titration of acidic aerosol and acidity change by OS formation (Sect. 3.5). Reactions in the inorganic phase occur only in the presence of water ( $\mathrm{RH}>$ efflorescence relative humidity $(\mathrm{ERH})$ ). We assume that $\mathrm{OM}_{\mathrm{AR}}$ is nonvolatile (Garland et al., 2006; Kleindienst et al., 2006; Cao and Jang, 2007).

6. The partitioning module approached by Schell et al. (2001) has been modified by inclusion of $\mathrm{OM}_{\mathrm{AR}}$ (Cao and Jang, 2010) to estimate $\mathrm{OM}_{\mathrm{P}}$ based on a mass balance of organic compounds between the gas and particle phases (Sect. 3.6).

The UNIPAR model was coded using Fortran. In the following sections, the model components are described in detail in order of computation in the UNIPAR model. 


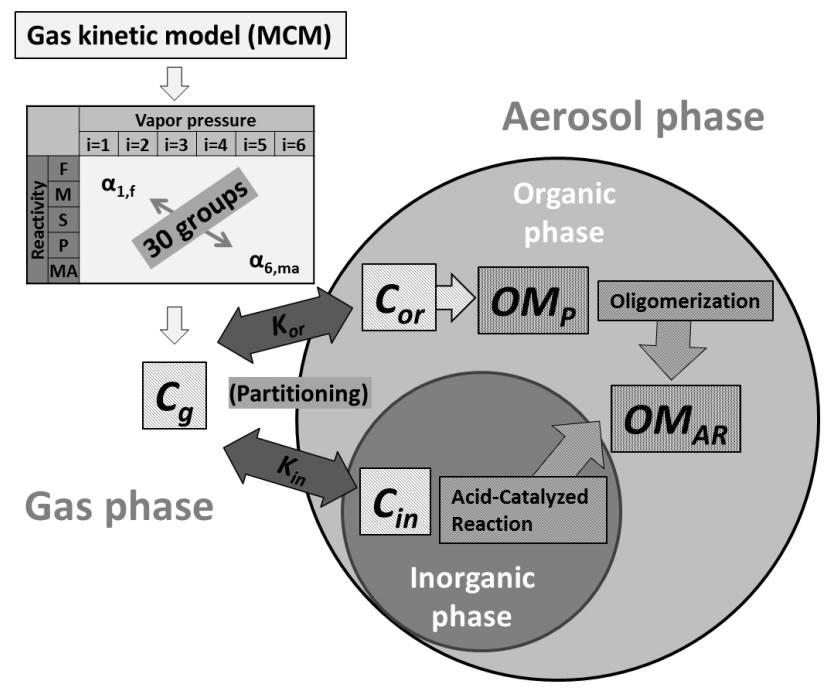

Fig. 1. Conceptual structure of the UNIPAR model. $\alpha_{i, j}$ is the mass-based stoichiometric coefficient. Reactivity F, M, S, P and MA indicate the fast, medium, slow, nonreactivity and multi-alcohol lumping group, respectively. $C$ and $K$ denote the concentration ( $\mu \mathrm{g} \mathrm{m}^{-3}$ of air) of lumping species and the partitioning coefficient $\left(\mathrm{m}^{3} \mu \mathrm{g}^{-1}\right)$, respectively. Subscripts "g", "or", and "in" denote gas, organic, and inorganic aerosol phases, respectively. $\mathrm{OM}_{\mathrm{P}}$ and $\mathrm{OM}_{\mathrm{AR}}$ are the concentrations $\left(\mu \mathrm{g} \mathrm{m}^{-3}\right)$ of organic matter $(\mathrm{OM})$ produced by partitioning and aerosol-phase reactions, respectively.

\subsection{Gas-phase chemistry}

The oxidation of reactive organic gas (ROG) (e.g., AVOC) and the resulting oxygenated products are predicted using an explicit gas-kinetic mechanism (MCM V3.2) integrated with Morpho, a gas-kinetic chemical solver (Jeffries et al., 1998). Because not all the reactions related to atmospheric VOC chemistry have been investigated, a fundamental assumption in the construction of the MCM is that the kinetics of a large number of unknown chemical reactions are defined with the use of structure-reactivity relationship (SRR). The SRR method semi-empirically estimates the rate constant using group rate constants and the influence of neighboring substituent, which is determined using the studied reactions of a smaller subset of similar chemical species (Kwok and Atkinson, 1995; Jenkin et al., 1997; Atkinson et al., 2001). The products derived from the explicit gas-kinetic mechanisms provide the information required for both partitioning (product volatility) and aerosol-phase reactions (product reactivity) through the oxidized product molecular structures.

\subsection{Product lumping structure}

The oxygenated products produced from the MCM simulation are lumped into 30 groups based on their vapor pressures (6 levels: $10^{-8}, 10^{-6}, 10^{-5}, 10^{-4}, 10^{-3}, 10^{-2} \mathrm{~mm} \mathrm{Hg}$ ) at $298 \mathrm{~K}$ and aerosol-phase reaction reactivities (5 levels: fast $[\mathrm{F}]$, medium $[\mathrm{M}]$, slow $[\mathrm{S}]$, nonreactive $[\mathrm{P}]$ and multi-alcohol
[MA]). The reactivity for aerosol-phase reaction is determined based on product functional groups (Sect. S2) assuming that aldehydes and epoxides are highly reactive in aerosol phase. Many laboratory studies have reported high reactivity of the product containing an aldehyde or epoxide functional groups (Jang and Kamens, 2001; Jang et al., 2003; Lal et al., 2012; Iinuma et al., 2009). The lumped products are used to construct the mass-based stoichiometric coefficient $\left(\alpha_{i, j}\right)$ matrix, the major set of parameters used to describe the concentrations of organic compounds in multiphase as shown in Eq. (1) below.

$$
\text { ROG + oxidant } \rightarrow \sum_{\substack{i=1-6 \\ j=\mathrm{F}-\mathrm{MA}}} \alpha_{i, j} L_{i, j},
$$

where $L_{i, j}$ is lumping species. The detailed description of product lumping is shown in the Supplement (Sect. S2). The lists of products of each lumping group for toluene and 135TMB are shown in Figs. S2 and S3 in the Supplement.

In the UNIPAR model, the dependence of aromatic SOA formation on $\mathrm{NO}_{\mathrm{x}}$ conditions was treated by parameterizing the $\alpha_{i, j}$ matrix under different $\mathrm{NO}_{\mathrm{x}}$ conditions. The photooxidation reactions of toluene or 135-TMB were simulated over a range of $\mathrm{VOC} / \mathrm{NO}_{\mathrm{x}}$ ratios (ppbC/ppb, 4.5-90) using the MCM V3.2 (details in Sect. S3). Then, regression equations of $\alpha_{i, j}$ as functions of the $\mathrm{VOC} / \mathrm{NO}_{\mathrm{x}}$ ratio were obtained from the simulation results (Tables S3 and S4 in the Supplement) and built into the Fortran code.

\subsection{Product concentrations among gas, organic and inorganic aerosol phases}

Under the assumption of organic/inorganic-phase separation, the estimation of concentration ( $\mu \mathrm{g} \mathrm{m}^{-3}$ of air) of lumping species, $i$, in the gas phase $\left(C_{\mathrm{g}, i}\right)$, organic phase $\left(C_{\mathrm{or}, i}\right)$ and inorganic phase $\left(C_{\mathrm{in}, i}\right)$ is derived from two gas-particle partitioning coefficients, $K_{\mathrm{or}, i}\left(\mathrm{~m}^{3} \mu \mathrm{g}^{-1}, \mathrm{~g} \leftrightarrow\right.$ or $)$ and $K_{\mathrm{in}, i}$ $\left(\mathrm{m}^{3} \mu \mathrm{g}^{-1}, \mathrm{~g} \leftrightarrow \mathrm{in}\right)$.

$$
\begin{gathered}
K_{\mathrm{or}, i}=\frac{C_{\mathrm{or}, i}}{C_{\mathrm{g}, i} \mathrm{OM}_{\mathrm{T}}}, \\
K_{\mathrm{in}, i}=\frac{C_{\mathrm{in}, i}}{C_{\mathrm{g}, i} M_{\mathrm{in}}},
\end{gathered}
$$

where $\mathrm{OM}_{\mathrm{T}}$ (SOA mass) is the total organic aerosol mass concentration $\left(\mu \mathrm{g} \mathrm{m}^{-3}\right.$ of air) and $M_{\mathrm{in}}$ is the inorganic aerosol mass concentration ( $\mu \mathrm{g} \mathrm{m}^{-3}$ of air). Both $K_{\mathrm{or}, i}$ and $K_{\text {in, } i}$ are estimated using Pankow's gas-particle absorption partition model (Eq. S1) (Pankow, 1994). In calculation of $K_{\mathrm{or}, i}$, the activity coefficients $\left(\gamma_{\mathrm{or}, i}\right)$ of lumping species in the organic phase are assumed as unity (Jang and Kamens, 1998). In estimation of activity coefficients $\left(\gamma_{\mathrm{in}, i}\right)$ of organic compounds in the inorganic aqueous phase $\left(\mathrm{SO}_{4} / \mathrm{NH}_{4} /\right.$ water$)$, although the modeling efforts have been made (Zuend et al., 2011), the model predictions are limited 
due to the complexity of organic compounds and the lack of a database. So, in this study, $\gamma_{\text {in }, i}$ was semi-empirically estimated. First, the activity coefficient of an organic compound was estimated under the saturated condition in pure water using Hansen's solubility parameter method (Barton, 1991) then corrected to the activity coefficient in salted aqueous phase at $50 \% \mathrm{RH}$ using the empirically obtained relationship between solubility of organic compounds in pure water and that in aqueous inorganic aerosol. For the solubility of organic compounds in inorganic aerosol, literature solubility data for $\mathrm{NaCl}$ aqueous solution were used because of the lack of literature data for $\mathrm{SO}_{4} / \mathrm{NH}_{4} /$ water. Detailed estimation of the activity coefficient of lumping species in the inorganic aqueous phase is described in the Supplement (Sect. S4).

The concentrations of each lumping species in the gas, organic aerosol, and inorganic aerosol phases are derived from Eqs. (2) and (3).

$$
\begin{gathered}
C_{\mathrm{g}, i}=\frac{1}{1+K_{\mathrm{or}, i} \mathrm{OM}_{\mathrm{T}}+K_{\mathrm{in}, i} M_{\mathrm{in}}} C_{\mathrm{T}, i}, \\
C_{\mathrm{or}, i}=\frac{K_{\mathrm{or}, i} \mathrm{OM}_{\mathrm{T}}}{1+K_{\mathrm{or}, i} \mathrm{OM}_{\mathrm{T}}+K_{\mathrm{in}, i} M_{\mathrm{in}}} C_{\mathrm{T}, i}, \\
C_{\mathrm{in}, i}=\frac{K_{\mathrm{in}, i} M_{\mathrm{in}}}{1+K_{\mathrm{or}, i} \mathrm{OM}_{\mathrm{T}}+K_{\mathrm{in}, i} M_{\mathrm{in}}} C_{\mathrm{T}, i},
\end{gathered}
$$

where $C_{\mathrm{T}, i}\left(\mu \mathrm{g} \mathrm{m}^{-3}\right.$ of air, $\left.C_{\mathrm{T}, i}=C_{\mathrm{g}, i}+C_{\mathrm{or}, i}+C_{\mathrm{in}, i}\right)$ is the total concentration of lumping species, $i$. The resulting $C_{\mathrm{or}, i}$ and $C_{\mathrm{in}, i}$ are applied to the calculation of $\mathrm{OM}_{\mathrm{AR}}$ through aerosol-phase reactions as shown in the next section and the Supplement (Sect. S5).

\subsection{SOA formation $\left(\mathrm{OM}_{\mathrm{AR}}\right)$ by aerosol-phase reactions}

$\mathrm{OM}_{\mathrm{AR}}$ is described by two processes: (1) the oligomerization reaction in the organic phase and (2) the acid-catalyzed reaction in the inorganic phase. $\mathrm{OM}_{\mathrm{AR}}$ is estimated using the analytical solution of reactions of lumping species in both organic and inorganic phases (Supplement, Sect. S5). The reactions in both the organic phase (Eq. 7) and inorganic phase (Eq. 8) are derived based on a second-order kinetic dimerization reaction (Odian, 1981).

$$
\begin{aligned}
& \frac{\mathrm{d} C_{\mathrm{or}, i}^{\prime}}{\mathrm{d} t}=-k_{\mathrm{o}, i} C_{\mathrm{or}, i}^{\prime}{ }^{2} \quad \text { (In the organic phase), } \\
& \frac{\mathrm{d} C_{i n, i}^{\prime}}{\mathrm{d} t}=-k_{\mathrm{AC}, i} C_{\mathrm{in}, i}^{\prime}{ }^{2} \text { (In the inorganic phase), }
\end{aligned}
$$

where $C_{\mathrm{or}, i}^{\prime}$ and $C_{\mathrm{in}, i}^{\prime}$ are the aerosol-based concentrations (mol L ${ }^{-1}$ of medium) of lumping species, $i$, in the organic and inorganic aerosol phases, respectively. The acidcatalyzed reaction rate constants $\left(k_{\mathrm{AC}, i}\right)\left(\mathrm{L} \mathrm{mol}^{-1} \mathrm{~s}^{-1}\right)$ are calculated by the following equation (Jang et al., 2006).

$k_{\mathrm{AC}, i}=10^{0.12 \mathrm{pK}_{\mathrm{BH}}^{+}+0.64 X+1.61 I_{i}+\log \left(a_{\mathrm{in}, \mathrm{w}}\left[\mathrm{H}^{+}\right]\right)-4.1} M_{\mathrm{in}}+k_{\mathrm{ACo}, i}$, where $\mathrm{pK}_{\mathrm{BH}}$ is the protonation equilibrium constant of the base, $X$ is excess acidity, $I$ is the heterogeneous reactivity parameter, and $a_{\mathrm{in}, \mathrm{w}}$ and $\left[\mathrm{H}^{+}\right]$are the activity of water and proton concentration (mol L-1 of inorganic aerosol). $k_{\mathrm{ACo}}$ stands for the acid-catalyzed reaction rate of the dilute condition (neutral wet inorganic aerosol). $k_{\mathrm{ACo}}, \mathrm{pK}_{\mathrm{BH}^{+}}$and $I$ are dependent on reactivity (F, M, S) of the compound, $i$. The $\left[\mathrm{H}^{+}\right]$of inorganic aerosol, and aerosol water concentrations, which are major factors in acid-catalyzed reactions, were estimated using E-AIM II. Similar to $k_{\mathrm{AC}, i}$, the oligomerization reaction rate constants $\left(k_{\mathrm{o}, i}\right)\left(\mathrm{L} \mathrm{mol}^{-1} \mathrm{~s}^{-1}\right)$ are determined at three levels based on reactivity of $i . k_{\mathrm{o}, i}$ is determined by multiplying $k_{\mathrm{AC}, 0}$ by a factor (0.13), which was determined by fitting the simulated OM to the measured OM using SOA data in the absence of the inorganic aerosol (Table 1).

When RH is lower than the ERH of the aerosol, the aerosol becomes crystalized and SOA cannot form by acidcatalyzed reactions in the inorganic phase. The ERHs of the $\mathrm{NH}_{4} / \mathrm{SO}_{4} /$ water aerosol system were estimated from the model study of Colberg et al. (2002). We assume that the ERH of inorganic species is not affected by organic products. Bertram et al. (2011) have recently reported that the ERH of inorganic salt (ammonium sulfate) is not changed by SOA products when $\mathrm{O}: \mathrm{C}$ is less than 0.7 .

The amount of OM formed by aerosol-phase reactions $\left(\Delta \mathrm{OM}_{\mathrm{AR}}\right)$ is same as the consumption of the total concentration of compound $\left(-\Delta C_{\mathrm{T}}\right)$ based on a mass balance. Therefore, the $\Delta \mathrm{OM}_{\mathrm{AR}}$ can be expressed as

$\Delta \mathrm{OM}_{\mathrm{AR}}=-\sum_{i} \Delta C_{\mathrm{T}, i}=-\sum_{i} \int \mathrm{d} C_{\mathrm{T}, i}$.

By combining Eqs. (2)-(8), the kinetic equation of $C_{\mathrm{T}, i}$ can be expressed as follows. (The detailed derivation is shown in the Supplement, Sect. S5).

$\frac{\mathrm{d} C_{\mathrm{T}, i}}{\mathrm{~d} t}=-k_{\mathrm{o}, i} C_{\mathrm{or}, i}{ }^{2}\left(\frac{\mathrm{MW}_{i} \mathrm{OM}_{\mathrm{T}}}{\rho_{\mathrm{or}} 10^{3}}\right)-k_{\mathrm{AC}, i} C_{\mathrm{in}, i}{ }^{2}\left(\frac{\mathrm{MW}_{i} M_{\mathrm{in}}}{\rho_{\mathrm{in}} 10^{3}}\right)$,

where $\rho_{\text {or }}$ and $\rho_{\text {in }}$ are the densities of the organic and inorganic aerosol phases, respectively. In this model, the $\rho_{\text {or }}$ was assumed as a constant $\left(1.4 \mathrm{~g} \mathrm{~cm}^{-3}\right)$ based on the previously reported studies (Ng et al., 2007; Sato et al., 2007; Nakao et al., 2011) for aromatic SOA. The $\rho_{\text {in }}$ was calculated dynamically using the E-AIM model as a function of $\mathrm{RH}$ and a numerical indicator for inorganic compositions related to aerosol acidity $\left(\mathrm{Fs}=\left[\mathrm{SO}_{4} /\left(\mathrm{SO}_{4}+\mathrm{NH}_{4}\right)\right] . \mathrm{OM}_{\mathrm{AR}}\right.$ is estimated from the analytical solution of Eq. (11) in the UNIPAR model.

\subsection{Change of aerosol acidity by OS formation}

The formation of OS from the reaction of organic species with sulfuric acid reduces aerosol acidity. In a recent study, $\mathrm{Li}$ and Jang (2013) reported that esterification of sulfuric acid with alcohols and aldehydes in the aerosol phase decrease 
Table 1. SOA chamber experimental conditions and resulting SOA data.

\begin{tabular}{|c|c|c|c|c|c|c|c|c|c|c|}
\hline NO. & Experiment ${ }^{\mathrm{a}}$ & AVOC & $\begin{array}{r}\text { Initial } \\
\text { AVOC } \\
(\mathrm{ppb})\end{array}$ & $\begin{array}{r}\text { Initial } \\
\text { NO } \\
(\mathrm{ppb})\end{array}$ & $\begin{array}{r}\text { Initial } \\
\mathrm{NO}_{2}(\mathrm{HONO}) \\
(\mathrm{ppb})\end{array}$ & $\begin{array}{r}\mathrm{VOC} / \mathrm{NO}_{\mathrm{x}} \\
(\mathrm{ppbC} / \mathrm{ppb})\end{array}$ & $\begin{array}{r}\text { Initial } \\
\mathrm{SO}_{2} \\
(\mathrm{ppb})\end{array}$ & $\begin{array}{r}\text { SOA } \\
\text { yield }^{b} \\
(\%)\end{array}$ & $\begin{array}{l}\mathrm{RH} \\
(\%)\end{array}$ & $\begin{array}{r}\text { Temp. } \\
(\mathrm{K})\end{array}$ \\
\hline 1 & $01 / 06 / 12 \mathrm{E}$ & Toluene & 190 & 35 & $35(40)$ & 12.09 & 50 & $18.9 \pm 1.7$ & $81-18$ & $280-306$ \\
\hline 2 & 01/06/12W & Toluene & 190 & 40 & $20(35)$ & 14.78 & - & $13.3 \pm 1.2$ & $81-18$ & $280-306$ \\
\hline 3 & $02 / 09 / 12 \mathrm{E}$ & Toluene & 175 & 180 & $30(35)$ & 5.00 & 46 & $15.3 \pm 1.4$ & $83-21$ & $280-307$ \\
\hline 4 & $02 / 09 / 12 \mathrm{~W}$ & Toluene & 180 & 180 & $31(35)$ & 4.52 & - & $9.3 \pm 0.8$ & $83-21$ & $280-307$ \\
\hline 5 & $05 / 18 / 12 \mathrm{E}$ & 135-TMB & 160 & 195 & $48(75)$ & 5.14 & - & $4.9 \pm 0.4$ & $95-14$ & $290-317$ \\
\hline 6 & $05 / 18 / 12 \mathrm{~W}$ & 135-TMB & 170 & 206 & $16(75)$ & 6.06 & 40 & $7.3 \pm 0.7$ & $95-14$ & $290-317$ \\
\hline 7 & $05 / 20 / 12 \mathrm{E}$ & 135-TMB & 165 & 105 & $8(20)$ & 11.12 & - & $3.4 \pm 0.3$ & $90-13$ & $290-317$ \\
\hline 8 & $05 / 20 / 12 \mathrm{~W}$ & 135-TMB & 165 & 100 & $7(15)$ & 12.12 & 43 & $5.7 \pm 0.5$ & $90-13$ & $290-317$ \\
\hline 9 & $06 / 20 / 12 \mathrm{E}$ & Toluene & 165 & 90 & $5(15)$ & 10.50 & $35^{\mathrm{c}}$ & $15.6 \pm 1.4$ & $83-27$ & $295-317$ \\
\hline
\end{tabular}

${ }^{\mathrm{a}} \mathrm{E}$ and $\mathrm{W}$ denote the east and west chamber. ${ }^{\mathrm{b}} \mathrm{SOA}$ yields are determined at 14:00 EST for toluene and at 11:00 EST for 135-TMB, while the uncertainties of SOA yields are estimated from the uncertainties of OM and $\triangle$ ROG by the propagation of uncertainty $(\mathrm{Ku}, 1966) .{ }^{\mathrm{c}}$ Mass concentration of inorganic seed (sulfuric acid) ( $\mu \mathrm{g} \mathrm{m}^{-3}$ ).

the aerosol acidity because the chemical process transforms sulfuric acid into dialkylsulfates. This change can affect the acid-catalyzed reaction for SOA formation, requiring an estimation of the modified acidity by OS formation. In the model, the removal of a sulfate ion by OS formation is estimated using Eq. (12) at each time step (Fig. 2).

$$
\begin{aligned}
& \text { OS conversion factor }=\frac{\left[\mathrm{SO}_{4}^{2-}\right]_{\mathrm{old}}-\left[\mathrm{SO}_{4}^{2-}\right]_{\text {new }}}{\left[\mathrm{SO}_{4}^{2-}\right]_{\mathrm{old}}} \\
& =\frac{\Delta \mathrm{OS}}{\left[\mathrm{SO}_{4}^{2-}\right]_{\mathrm{old}}}=1-\frac{1}{1+f_{\mathrm{OS}} \frac{N_{\mathrm{OS}}}{\left[\mathrm{SO}_{4}^{2-}\right]_{\text {free }}}},
\end{aligned}
$$

where $\left[\mathrm{SO}_{4}^{2-}\right]_{\text {old }}$ and $\left[\mathrm{SO}_{4}^{2-}\right]_{\text {new }}$ are sulfate concentrations (mol L ${ }^{-1}$ of inorganic aerosol) before and after sulfate consumption by OS formation, respectively. Before the formation of new OS at each time step, free sulfate $\left(\left[\mathrm{SO}_{4}^{2-}\right]_{\text {free }}\right)$ (mol L ${ }^{-1}$ of inorganic aerosol) that can form OS is calculated by excluding a sulfate ion in ammonium sulfate from the total ionic sulfate $\left[\mathrm{SO}_{4}^{2-}\right]_{\text {ion }}$ that is not associated with OS: $\left[\mathrm{SO}_{4}^{2-}\right]_{\text {free }}=\left[\mathrm{SO}_{4}^{2-}\right]_{\text {ion }}-0.5\left[\mathrm{NH}_{4}^{+}\right]$. OS conversion factor is calculated based on available $\left[\mathrm{SO}_{4}^{2-}\right]_{\text {free }} N_{\mathrm{OS}}$ is the parameter to count the functional groups that can react with sulfate to form OS. Aldehyde, epoxide and alcohol groups are counted as the OS-formable functional groups because of their reactivity with sulfate. The semi-empirical parameter $f_{\mathrm{OS}}$ is obtained by comparison of model simulation and acidity measurements for a separate SOA experiment in the presence of sulfuric acid seed aerosol (Exp. on 20 June 2012 in Table 1). A detailed calculation of $N_{\mathrm{OS}}$ and a description of $f_{\mathrm{OS}}$ are shown in the Supplement (Sect. S6). When $N_{\mathrm{OS}}$ is very high, $\triangle \mathrm{OS}$ becomes high at a given $\left[\mathrm{SO}_{4}^{2-}\right]_{\text {free. When }}$ $N_{\text {OS }}$ is very small, the OS conversion factor is nearly zero. Based on the inorganic species from the previous time step (except OS sulfates) and the new ionic species added into the system, both $a_{\text {in,w }}$ and $\left[\mathrm{H}^{+}\right]$are calculated at each time step using the inorganic thermodynamic model. The new $a_{\text {in,w }}$ and $\left[\mathrm{H}^{+}\right]$are applied to Eq. (9) for estimating $k_{\mathrm{AC}, i}$.

\subsection{SOA formation by partitioning $\left(O M_{P}\right)$}

$\mathrm{OM}_{\mathrm{P}}$ is estimated using the partitioning module derived by Schell et al. (2001) based on six volatility bins $\left(10^{-8}, 10^{-6}\right.$, $10^{-5}, 10^{-4}, 10^{-3}, 10^{-2} \mathrm{~mm} \mathrm{Hg}$ at $298 \mathrm{~K}$ in Sect. 3.2). In UNIPAR, the partitioning module has been modified by inclusion of nonvolatile $\mathrm{OM}_{\mathrm{AR}}$ (Cao and Jang, 2010) and reconstructed into $\mathrm{OM}_{\mathrm{P}}$ based on a mass balance of organic compounds between the gas and particle phases. After $\mathrm{OM}_{\mathrm{AR}}$ calculation, $C_{\mathrm{g}, i}$ and $C_{\mathrm{or}, i}$ are recalculated numerically using Eq. (13) (Press et al., 1992).

$$
\begin{aligned}
& \mathrm{OM}_{\mathrm{P}}=\sum_{i} C_{\mathrm{or}, i} \\
& =\sum_{i}\left[C_{\mathrm{T}, i}-\mathrm{OM}_{\mathrm{AR}, i}-C_{\mathrm{g}, i}^{*} \frac{\frac{C_{\mathrm{or}, i}}{\sum_{k}} \frac{C_{\mathrm{or}, k}}{\mathrm{MW}_{k}}+\frac{\mathrm{OM}_{\mathrm{AR}}}{\mathrm{MW}_{\mathrm{oli}}}+\mathrm{OM}_{0}}{\mathrm{OM}_{0}}\right],
\end{aligned}
$$

where $C_{\mathrm{g}, i}^{*}$ is the saturated gas-phase concentration lumping species, $i ; \mathrm{MW}_{k}$ is the molecular weight of lumping species, $k$; and $\mathrm{MW}_{\text {oli }}$ is the average molecular weight of oligomers formed from aerosol-phase reactions. $\mathrm{OM}_{0}$ is the mass concentration of preexisting organic particulate matter $\left(\mathrm{mol} \mathrm{m}^{-3}\right) . C_{\mathrm{in}, i}$ is relatively very small compared to $C_{\mathrm{g}, i}$ and $C_{\text {or }, i}$, and the term $K_{\mathrm{in}, i} M_{\mathrm{in}}$ is also very small compared to the term $K_{\mathrm{or}, i} \mathrm{OM}_{\mathrm{T}}$ in Eqs. (4)-(6). Hence, the estimations of $C_{\mathrm{g}, i}$ and $C_{\mathrm{or}, i}$ are approached by the $\mathrm{OM}_{\mathrm{P}}$ module at the end of each time step excluding $C_{\mathrm{in}, i}$ (Fig. 2).

\subsection{Model simulation}

To estimate SOA formation over the course of a chamber experiment under dynamically changing ambient conditions (temperature, $\mathrm{RH}$ and sunlight intensity) and inorganic aerosol mass and composition, the model calculates SOA 


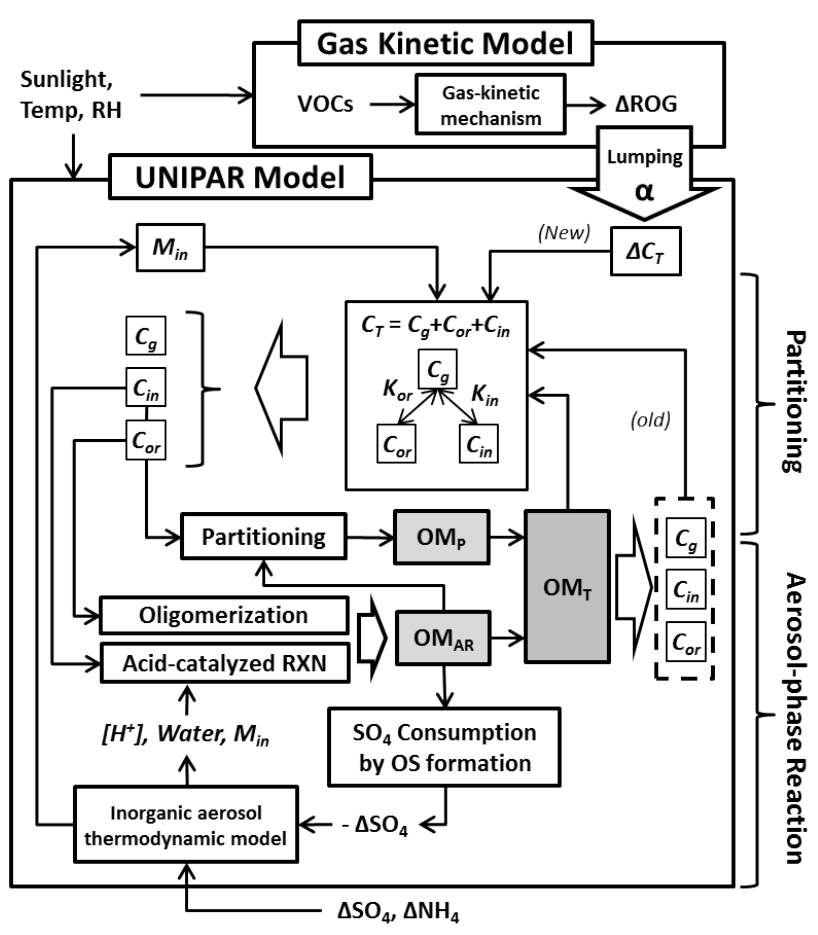

Fig. 2. Computational flow of the UNIPAR model. $\triangle R O G$ is the reacted organic parent compound during $\Delta t$, and $\alpha_{i, j}$ is the massbased stoichiometric coefficient. $C$ and $K$ represent the concentration of lumping species and partitioning coefficient, respectively, and the subscription of "g", "or", and "in" denote gas, organic, and inorganic aerosol phases, respectively. $\mathrm{OM}_{\mathrm{P}}$, and $\mathrm{OM}_{\mathrm{AR}}$ are the concentrations of organic matter produced by partitioning and aerosol-phase reactions, respectively. $M_{\text {in }}$ is the concentration of inorganic aerosol.

mass at each time interval ( $\Delta t=3 \mathrm{~min}$ ) by updating the input parameters. In this study, six input parameters were used: initial $\mathrm{VOC} / \mathrm{NO}_{\mathrm{x}}$ ratio, decay of precursor AVOC $(\triangle \mathrm{ROG})$ (from MCM simulation), increments of sulfate $\left(\triangle \mathrm{SO}_{4}^{2-}\right)$ and ammonium $\left(\Delta \mathrm{NH}_{4}^{+}\right)$ion concentration (from PILS-IC), temperature and $\mathrm{RH}$. For the prediction of $\mathrm{OM}_{\mathrm{P}}$, the accumulated concentrations of each lumping group are used with the exclusion of $\mathrm{OM}_{\mathrm{AR}}$, from the previous time step.

\section{Result and discussion}

\subsection{Gas-phase model simulation vs. experimental data}

According to previous studies (Wagner et al., 2003; Johnson et al., 2004; Bloss et al., 2005), the kinetic mechanisms of aromatic hydrocarbons in MCM overestimate ozone peaks and underestimate precursor decay due to the low production of $\mathrm{OH}$ radicals. Hence, an artificial $\mathrm{OH}$ radical was added to the toluene mechanism in this study. The artificial $\mathrm{OH}$ radical production rate was determined by comparing the simulated toluene decay to the measured data. Several pos- sible explanations for the addition of artificial $\mathrm{OH}$ radicals were suggested in the study by Bloss et al. (2005): for example, the uncertainty in yields of the reactive oxygenated intermediates produced via degradation of aromatic products, unknown photolysis rates of organic compounds, and missing pathways for $\mathrm{OH}$ radical generation in MCM. Moreover, chemistry of a variety of peroxy radicals $\left(\mathrm{RO}_{2}\right)$ in $\mathrm{MCM}$ was oversimplified using surrogate coefficients instead of explicit mechanisms. Such simplified $\mathrm{RO}_{2}$ chemistry can cause the discrepancy between the measured and the predicted concentrations of $\mathrm{OH}$ radicals. The $\mathrm{OH}$ radical production rate for the toluene mechanism of this study was approximately $2.0 \times 10^{8}$ molecules $\mathrm{cm}^{3} \mathrm{~s}^{-1}$, which is smaller than previously reported values $\left(\sim 4.0 \times 10^{8}\right.$ molecules $\left.\mathrm{cm}^{3} \mathrm{~s}^{-1}\right)$ (Bloss et al., 2005; Cao and Jang, 2010). The discrepancy between the artificial $\mathrm{OH}$ radical production rate in this study and those previously published may be attributed to different experimental conditions such as initial VOC (200 vs. $700 \mathrm{ppb}$ ) and $\mathrm{NO}_{\mathrm{x}}$ concentrations as well as meteorological conditions. In the same manner, the production rate of artificial $\mathrm{OH}$ radicals for the 135-TMB mechanism was $1.7 \times 10^{8}$ molecules $\mathrm{cm}^{3} \mathrm{~s}^{-1}$.

Toluene experiments were conducted for $12 \mathrm{~h}$ (07:0017:00 EST), but 135-TMB experiments could only be conducted for $5 \mathrm{~h}$ (07:00-12:00 EST) because of the fast reactivity of 135-TMB (all 135-TMB was consumed before 12:00 EST). Overall, VOC decay, $\mathrm{NO} / \mathrm{NO}_{2}$ conversion and $\mathrm{O}_{3}$ production are reasonably predicted. The comparison of gas-phase experimental data with simulation results for toluene and 135-TMB in two different $\mathrm{NO}_{\mathrm{x}}$ conditions is shown in Fig. S8 (Supplement Sect. S7).

It is well known that $\mathrm{SO}_{2}$ can be oxidized through both gas-phase reactions with $\mathrm{OH}$ radicals and heterogeneous chemistry on the aqueous surface (aerosol and chamber wall). Due to the lack of the heterogeneous reaction mechanisms for the oxidation of $\mathrm{SO}_{2}$, sulfuric acid formation through the oxidation of $\mathrm{SO}_{2}$ was not predicted by explicit mechanisms. The sulfate concentrations measured by PILSIC were directly applied to the UNIPAR model to simulate the effect of inorganic species on SOA formation.

\subsection{Effect of $\mathrm{NO}_{\mathrm{x}}$ on aromatic SOA formation}

Figure 3 shows model simulations of both toluene SOA (Fig. 3a and b) and 135-TMB SOA (Fig. 3c and d) against experimental data with and without $\mathrm{SO}_{2}$ under two different $\mathrm{NO}_{\mathrm{x}}$ levels. The yields of toluene and 135-TMB SOA were determined at 14:00 and 11:00 EST, respectively. For toluene, SOA yields under the lower $\mathrm{NO}_{\mathrm{x}}$ condition (Fig. 3a, $18.9 \%$ with and $13.3 \%$ without $\mathrm{SO}_{2}$ ) were higher than those under the higher $\mathrm{NO}_{\mathrm{x}}$ condition (Fig. 3b, $15.3 \%$ with and $9.3 \%$ without $\mathrm{SO}_{2}$ ). This trend is consistent with other studies (Ng et al., 2007; Kroll et al., 2007). Overall, the UNIPAR model reasonably predicted measured OM concentrations of both high and low $\mathrm{NO}_{\mathrm{x}}$ conditions. However, during the later 

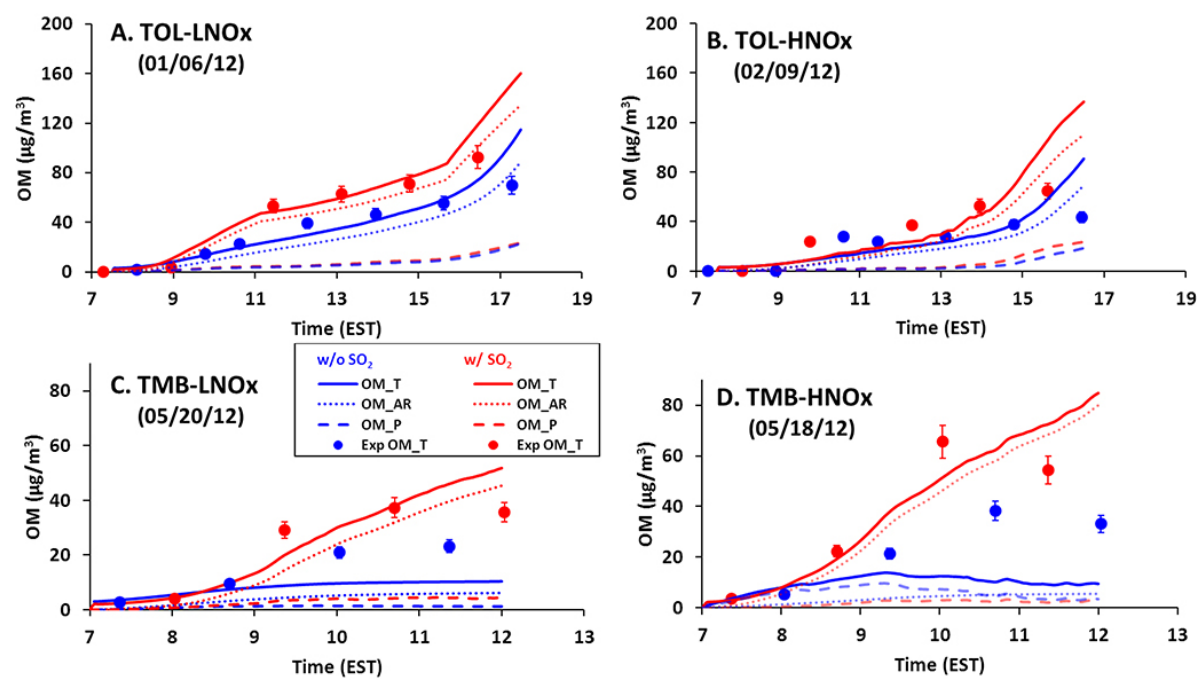

Fig. 3. Time profiles of measured (symbols) and simulated SOA mass concentrations for toluene SOA and 135-TMB SOA under low and high $\mathrm{NO}_{\mathrm{x}}$ conditions. The red and blue colors indicate experiments with and without $\mathrm{SO}_{2}$, respectively. Solid, dashed, and dotted lines represent total $\mathrm{OM}\left(\mathrm{OM}_{\mathrm{T}}\right)$, the $\mathrm{OM}$ from partitioning $\left(\mathrm{OM}_{\mathrm{P}}\right)$, and the $\mathrm{OM}$ from the aerosol-phase reaction $\left(\mathrm{OM}_{\mathrm{AR}}\right)$, respectively. The uncertainty associated with OM (about $9 \%$ ) is estimated from the uncertainties of OC measurements and particle wall loss correction.

part of the study (after 15:00 EST), the model tends to overestimate the measured OM concentrations. This may be due to the high sensitivity to temperature changes in the model and the adsorption of SVOCs to chamber walls at low temperatures. When the toluene chamber experiments were conducted (January-February), chamber temperature suddenly decreased after 15:00 EST (Fig. S4). Furthermore, to evaluate the model performance in a wider range of $\mathrm{NO}_{\mathrm{x}}$ levels, toluene $\mathrm{SOA}$ were simulated under various $\mathrm{NO}_{\mathrm{x}}$ conditions (VOC/ $\mathrm{NO}_{\mathrm{x}}$ ratio: 2-84, ppbC/ppb) (Fig. S9 in Sect. S8). The simulation results for the toluene SOA formation $\left(\mathrm{OM}_{\mathrm{T}}\right)$ showed a consistent trend with other laboratory studies ( $\mathrm{Ng}$ et al., 2007; Cao and Jang, 2010).

The trend of 135-TMB SOA yields is the opposite of the toluene SOA yields, showing higher SOA yields under higher $\mathrm{NO}_{\mathrm{x}}$ conditions $\left(7.3 \%\right.$ with $\mathrm{SO}_{2}, 4.9 \%$ without $\left.\mathrm{SO}_{2}\right)$ than those under lower $\mathrm{NO}_{\mathrm{x}}$ conditions $\left(5.7 \%\right.$ with $\mathrm{SO}_{2}, 3.4 \%$ without $\mathrm{SO}_{2}$ ). This result appears inconsistent with previous chamber studies (Wyche et al., 2009; Metzger et al., 2008; Rickard et al., 2010). This discrepancy may be partially explained by differences in environmental conditions between different chambers and various stages in multigeneration oxidation of products. Overall, the predicted OM accords well with observation for 135-TMB oxidation in the presence of $\mathrm{SO}_{2}$, but without $\mathrm{SO}_{2}$ the UNIPAR model underestimates OM compared to experimental data (Fig. $3 \mathrm{c}$ and d). The deviation of model prediction from observation can be caused by the uncertainty of the $\alpha_{i, j}$ matrix, which is affected by the reaction time. The actual 135-TMB SOA might be produced from more aged products than those used in the model, where the $\alpha_{i, j}$ matrix is determined at half of 135-TMB consumption.
Overall, aromatic SOA yields of this study are relatively low compared to those from other studies (Cao and Jang, 2010; $\mathrm{Ng}$ et al., 2007), although similar in the trend of $\mathrm{NO}_{\mathrm{x}}$ effects. Lower SOA yields than those using indoor chambers are often observed in outdoor chambers (Johnson et al., 2004). The temperature and sunlight for outdoor chambers have a diurnal pattern (Fig. S4 in the Supplement Sect. S3). In general, the light intensity of ambient sunlight facilitated in outdoor chambers is much stronger than indoor chambers. Johnson et al. (2004) reported low SOA yields using the outdoor chamber. For example, toluene SOA yields under low $\mathrm{NO}_{\mathrm{x}}$ were $4.63-5.14 \%$ and the SOA yields under high $\mathrm{NO}_{\mathrm{x}}$ were $2.05-3.57 \%$.

\subsection{Organosulfate formation}

The UNIPAR model estimates the formation of OS using the amount of consumed sulfate $\left(\mathrm{SO}_{4}^{2-}\right)$ estimated by Eq. (12) and the average MW of OS products. The average MW of OS, which changes dynamically depending on the change of the $\mathrm{OM}_{\mathrm{AR}}$ matrix over the course of the experiment, was predicted by the model. The predicted OS fraction of the total OM $\left(\mathrm{OS} / \mathrm{OM}_{\mathrm{T}}\right)$ from the model is illustrated in Fig. 4a for both toluene SOA and 135-TMB SOA under two different $\mathrm{NO}_{\mathrm{x}}$ conditions. In this study, the fraction of OS of the total $\mathrm{OM}\left(\mathrm{OS} / \mathrm{OM}_{\mathrm{T}}\right)$ was 0.095 for toluene $\mathrm{SOA}$ under the low $\mathrm{NO}_{\mathrm{x}}$ condition and 0.052 under the high $\mathrm{NO}_{\mathrm{x}}$ condition. For 135-TMB SOA, the fraction of OS $\left(\mathrm{OS} / \mathrm{OM}_{\mathrm{T}}\right)$ was 0.076 with the low $\mathrm{NO}_{\mathrm{x}}$ condition and 0.077 with the high condition. The predicted OS fractions of the total sulfates $\left(\left[\mathrm{SO}_{4}^{2-}\right]_{\mathrm{OS}} /\left[\mathrm{SO}_{4}^{2-}\right]_{\text {total }}\right)$ from the model reasonably agreed 

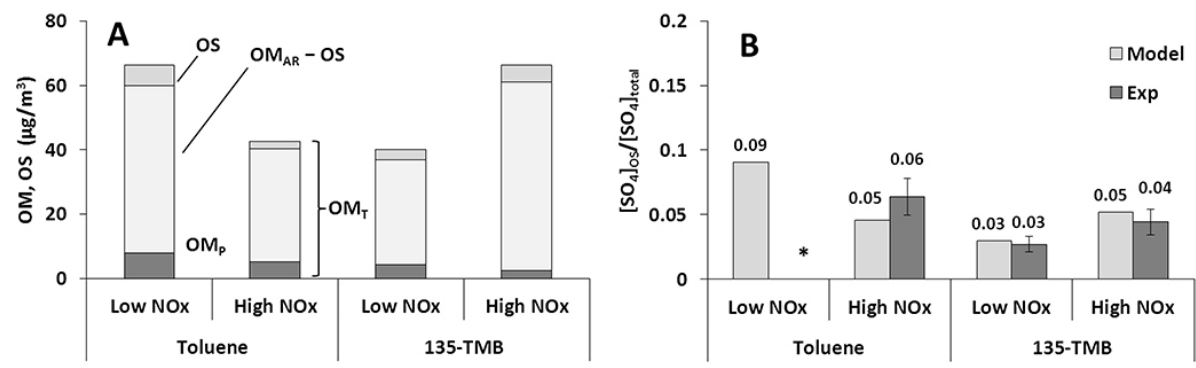

Fig. 4. Model-predicted fractions of $\mathrm{OM}_{\mathrm{P}}, \mathrm{OM}_{\mathrm{AR}}$, and OS of the total SOA for toluene SOA and 135-TMB SOA under two NO $\mathrm{N}_{\mathrm{x}}$ levels (low and high) (Experiments 1-8 in Table 1) (A). Comparison of the OS fraction of the total sulfate between model prediction and measurement using the C-RUV method and PILS-IC (B).The uncertainty associated with the ratio of OS to total sulfate is determined based on uncertainties of C-RUV (about $10 \%$ ) and PILS-IC measurements (about $10 \%$ ) by the propagation of uncertainty (Ku, 1966). ${ }^{*}$ No experimental data are available.

with experimentally measured values using the C-RUV and PILS-IC data (Fig. 4b).

\subsection{Effect of inorganic aerosol acidity on aromatic SOA formation}

In this study, the effect of inorganic aerosol acidity on aromatic SOA yields was evaluated in two ways: (1) SOA formation with and without $\mathrm{SO}_{2}$, and (2) $\mathrm{SOA}$ formation in the presence of different inorganic aerosols with varying $\mathrm{RH}$. In the presence of $\mathrm{SO}_{2}$, the mass concentrations and the compositions of inorganic aerosols dynamically changed due to the formation of sulfuric acid from the oxidation of $\mathrm{SO}_{2}$, neutralization with ammonia gas present in the background chamber air and the fluctuation of ambient RH over the course of the chamber experiments. For all toluene and 135-TMB experiments, $\mathrm{SOA}$ yields were higher in the presence of $\mathrm{SO}_{2}$ than without $\mathrm{SO}_{2}$ (Fig. 3). This suggests that the acidic inorganic aerosol contributed to an increased OM through acidcatalyzed reactions. With $\mathrm{SO}_{2}$, toluene $\mathrm{SOA}$ yields increased by $42 \%$ under the low $\mathrm{NO}_{\mathrm{x}}$ condition and by $65 \%$ under the high $\mathrm{NO}_{\mathrm{x}}$ condition (Table 1 and Fig. 3) compared to those without $\mathrm{SO}_{2}$. 135-TMB SOA increased by $68 \%$ under the low $\mathrm{NO}_{\mathrm{x}}$ conditions and by $49 \%$ under the high $\mathrm{NO}_{\mathrm{x}}$ condition. As shown in Fig. 3, the model also reasonably predicted acidity effects on both toluene and 135-TMB SOA.

In Figs. 3 and $4 a$, the large fraction of $\mathrm{OM}_{\mathrm{AR}}$ in the total OM means that most SOA forms via aerosol-phase reactions $\left(\mathrm{OM}_{\mathrm{AR}}\right)$. For the $\mathrm{SOA}$ without inorganic aerosol, $\mathrm{OM}_{\mathrm{AR}}$ is dominated by oligomerization in organic phase. For the SOA in the presence of inorganic aerosol, $\mathrm{OM}_{\mathrm{AR}}$ forms via both oligomerization in organic phase and the acid-catalyzed reaction in inorganic phase. These two reactions compete with each other for the consumption of reactive lumping species (monomer) (Eq. S18). The relative importance of oligomerization in organic phase and acid-catalyzed reaction in inorganic phase depends on the inorganic-to-organic-mass ratio in the total aerosol, aerosol acidity, RH, solubility of organic species in inorganic salt solution, and rate constants in each phase. Overall, under our experimental conditions, the acidcatalyzed reaction ( $\beta 2$ in Eq. S18) in the inorganic phase more significantly contributes to $\mathrm{OM}_{\mathrm{AR}}$ than oligomerization in organic phase ( $\beta 1$ in Eq. S18).

In the presence of inorganic aerosol, the sensitivity of SOA formation to aerosol acidity was also simulated using the UNIPAR model. For model simulation, toluene was oxidized under two different \%RHs (30 and 60) in the presence of four different inorganic aerosols: sulfuric acid, ammonium bisulfate (ABS), ammonium sulfate, and neutralization of sulfuric acid aerosol with ammonia (SA to AS) as shown in Fig. 5. For the lower humidity $(\% \mathrm{RH}=30)$, the SOA production is the highest with SA, followed by ABS, and the lowest with AS. At higher humidity ( $\% \mathrm{RH}=60, \mathrm{RH}>\mathrm{ERH}$ of AS), the acidity effect on SOA production is not distinguishable; i.e., there is no difference in SOA production between the ABS system and the AS system at RH $60 \%$. As shown in Eq. (S18), SOA yields in the presence of inorganic aerosol are influenced by $k_{\mathrm{AC}, i}$ linked to aerosol acidity (Eq. 9), $M_{\text {in }}$ (the amount of water and critical RH), and $\gamma_{\text {in, } i}$ associated with $K_{\mathrm{in}, i}$. At low $\mathrm{RH}, k_{\mathrm{AC}, i}$ is higher with more highly acidic aerosol (sulfuric acid) due to increased $\left[\mathrm{H}^{+}\right]$and $X$ (Eq. 9). The ERH of the highly acidic aerosol remains below the ambient RH, while the ERH of either neutral inorganic aerosol or weakly acidic inorganic aerosol can be above the certain ambient RH (e.g., $30 \%$ ) forming a crystalized inorganic aerosol (no acid-catalyzed reaction; see Sect. 3.4). At high $\mathrm{RH}$, the difference in $k_{\mathrm{AC}, i}$ between three different inorganic aerosols (Fig. 5) is relatively small. Because their ERH is below $60 \%$, all the systems represent acid-catalyzed reaction within inorganic seeded aqueous phase.

The OS formation in both SA and ABS systems influence the hygroscopic properties of inorganic aerosols through the consumption of sulfate ions $\left(\mathrm{SO}_{4}^{2-}\right)$ and decreasing particle acidity (decrease of the ratio of inorganic sulfate to ammonium ion). The reduction of $M_{\text {in }}$ due to OS formation can suppress the SOA formation mechanism through acidcatalyzed reactions in aqueous phase. As shown in Eqs. (S17) 

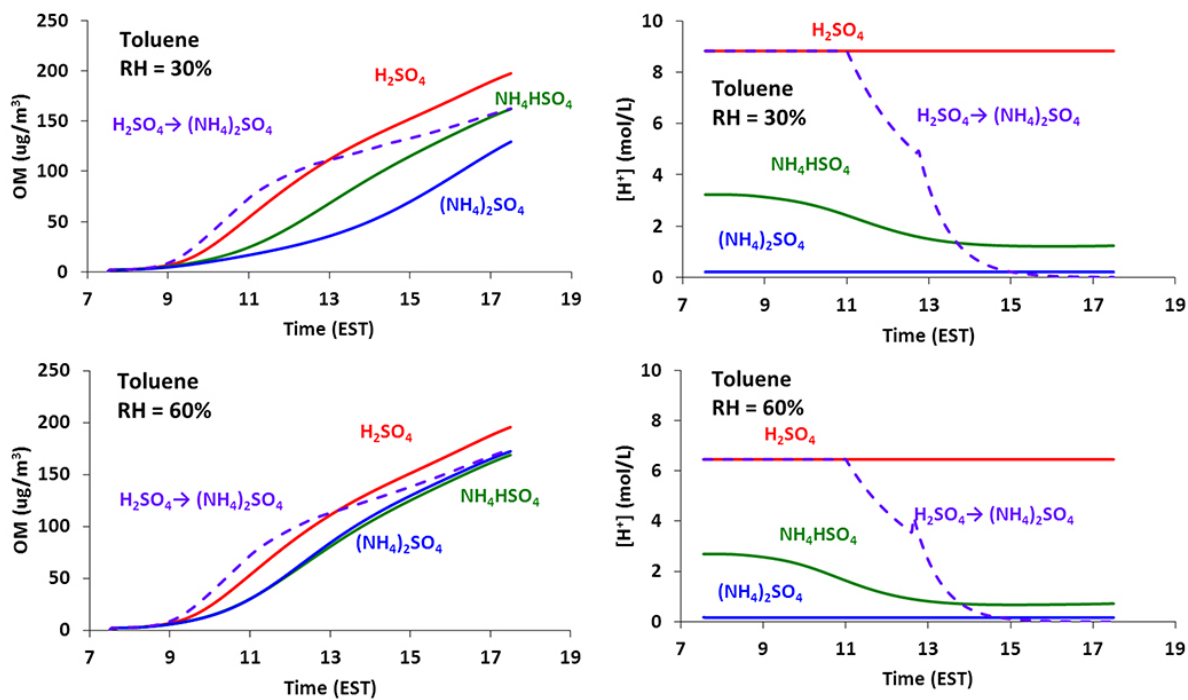

Fig. 5. Time profiles of the simulated $\mathrm{OM}$ and aerosol acidity $\left(\left[\mathrm{H}^{+}\right], \mathrm{mol} \mathrm{L}^{-1}\right.$ in inorganic aerosol) in four different inorganic aerosols: sulfuric acid (red), ammonium bisulfate (green), ammonium sulfate (blue), and sulfuric acid with ammonia neutralization (violet). To mimic atmospheric conditions in the model simulation, inorganic aerosol (e.g., sulfuric acid, ammonium bisulfate, and ammonium sulfate) is added into the chamber at the constant rate $\left(2.1 \mu \mathrm{g} \mathrm{m}^{-3} \mathrm{~h}^{-1}\right)$. The total amount of inorganic aerosol introduced into the chamber is $20 \mu \mathrm{g} \mathrm{m}^{-3}$. For the case of the neutralization of sulfuric acid with ammonia, sulfuric acid is added for the first $3.5 \mathrm{~h}$ (07:30 to 11:00 EST), and ammonia is added to the chamber between 11:00 and 17:30 EST. For the model simulation, both the sunlight data and the consumption of toluene employ data on Exp. 6 January 2012 at a constant temperature $(298.15 \mathrm{~K})$ at 30 and $60 \%$ RH.

and (S18), $\mathrm{OM}_{\mathrm{AR}}$ decreases with the reaction of $M_{\mathrm{in}}$ (the mass concentration of wet inorganic aerosol).

\section{Model uncertainty and implications}

The $\mathrm{OM}_{\mathrm{AR}}$ module in the UNIPAR model includes new aerosol-phase reactions such as the oligomerization in both organic and inorganic phases, acid-catalyzed reactions and OS formation. Such effort enables prediction of the effect of both $\mathrm{SO}_{2}$ and inorganic aerosol on SOA formation under various humidity conditions. The model also improved the prediction of aromatic SOA formation under various $\mathrm{NO}_{\mathrm{x}}$ concentrations through weighting of the lumping matrix as a function of $\mathrm{VOC} / \mathrm{NO}_{\mathrm{x}}$ ratios. Although the UNIPAR model is developed with many submodels (e.g., MCM, UNIFAC, aerosol-phase reaction, inorganic thermodynamics), it requires relatively few inputs at run time because the UNIPAR model is a self-contained Fortran coded module that uses the parameters predetermined outside the UNIPAR model and inputs (e.g., $\Delta \mathrm{ROG},\left[\mathrm{SO}_{4}^{2-}\right],\left[\mathrm{NH}_{4}^{+}\right], T, \mathrm{RH}$, and $\mathrm{VOC} / \mathrm{NO}_{\mathrm{x}}$ ratios) commonly available in regional/global air quality models.

In spite of the significant contribution of SOA to $\mathrm{PM}_{2.5}$, ambient simulations on regional/global scales have a consistent low bias compared to monitored organic aerosol (Morris et al., 2006; Carlton et al., 2008; Baek et al., 2011; Ervens et al., 2011; Simpson et al., 2007; Kleinman et al., 2008). Although the current SOA mechanism in regional models in- cludes newly identified pathways, a substantial negative bias, particularly in summertime, suggests that the current model is insufficient to describe SOA formation and future efforts should focus on identifying and incorporating new SOA formation mechanisms (Simon and Bhave, 2012). The UNIPAR model possibly would improve the predictability of SOA growth in humid conditions (summertime) due to the $\mathrm{OM}_{\mathrm{AR}}$ module that expresses reactions of organic compounds in inorganic aqueous phase. Figure 5 confirms the important role of aqueous phase for SOA production. When aerosol is acidic $\left(\mathrm{H}_{2} \mathrm{SO}_{4}\right.$ and $\left.\mathrm{NH}_{4} \mathrm{HSO}_{4}\right)$, OM production is relatively insensitive to RH. However, in the presence of ammonium sulfate, which is a typical inorganic constituent in ambient aerosol, OM production is significantly affected by RH. As shown in Fig. 5, the simulated OM at high RH $(60 \%)$ is significantly higher than that at low RH (30\%) in the presence of ammonium sulfate (e.g., nearly $100 \%$ in the middle of the day).

The major uncertainties in the UNIPAR model associated with model assumptions, semi-empirical equations used to describe aerosol chemistry, and thermodynamic parameters to estimate the distribution of products among multiple phases are as follows.

1. The distribution of stoichiometric coefficient $\left(\alpha_{i, j}\right)$ is influenced by prediction of oxygenated products using the explicit kinetic mechanisms (e.g., MCM). Most kinetic mechanisms of aromatic hydrocarbons in MCM have not been tested due to the lack of authentic standards. Only few aromatic SOA products have been 
identified, although much effort has been expended in aromatic SOA product identification. For example, in a recent study by Sato et al. (2012) using liquid chromatography-mass spectrometry (LC-MS), only $\sim 1 \mathrm{wt} \%$ of the total mass of aerosol products from the photooxidation of toluene was identified. In this study, major products predicted by MCM were glyoxal and methylglyoxal for toluene and methylglyoxal and 2-methyl-4-oxo-2-pentenal for 135-TMB. These products have been experimentally observed in many studies (Smith et al., 1999; Alvarez et al., 2007). The addition of artificial $\mathrm{OH}$ radicals in the mechanisms suggests that the explicit gas-kinetic mechanisms for AVOCs need further development. Although the $\alpha_{i, j}$ matrix (Fig. 2) was described considering an initial $\mathrm{VOC} / \mathrm{NO}_{\mathrm{x}}$ ratio (Sect. 4.2) and applied to dynamically express aerosol-phase reactions, the $\alpha_{i, j}$ matrix was limited in describing photochemical aging of gaseous compounds.

2. Vapor pressure calculation of organic products and its temperature dependency influence both the gasparticle partitioning process and aerosol reactions of organic products. Both the estimation method of vapor pressure and product lumping based on volatility can affect model prediction. Figure $6 \mathrm{a}$ and $\mathrm{b}$ illustrate the sensitivity of model prediction to variation of vapor pressure and enthalpy heat of vaporization $\left(H_{\mathrm{vap}}\right)$. The uncertainty of the vapor pressure estimated using the group contribution method of this study is a factor of 1.45 (about $75 \%$ ) (Zhao et al., 1999; Myrdal and Yalkowsky, 1997). The $H_{\text {vap }}$ of organic products in this study ranges from 50 to $150 \mathrm{~kJ} \mathrm{~mol}^{-1}$. The reported error associated with the estimation of $H_{\text {vap }}$ of this study is about $4 \%$ (upper boundary) (Gopinathan and Saraf, 2001; Kolska et al., 2005 ; ). To test the impact of the uncertainty of the estimation, vapor pressures were increased by $100 \%$ and decreased by $50 \%$ (factor of 1.5 ) (Fig. 6a) and $H_{\text {vap }}$ were increased/decreased by $10 \%$ (Fig. 6b).

3. The estimation of the activity coefficients $\left(\gamma_{i, j}\right)$ of organic compounds in the salted aqueous phase also has some uncertainty due to the lack of the data sets of solubility of organic compounds in various inorganic salt solutions. The semi-empirically estimated $\gamma_{i, j}$ influences $C_{\mathrm{in}, i}$ as well as $\mathrm{OM}_{\mathrm{AR}}$ (Sect. 3.3). Figure 6c shows the sensitivity of the SOA model due to the variation of $\gamma_{i, j}$ (increased by 3 times and decreased by one-third). When $\gamma_{\mathrm{in}, i}$ is increased by 3 times, $\mathrm{OM}_{\mathrm{AR}}$ approaches the value predicted in the absence of inorganic salt solution (lower boundary of $\mathrm{OM}_{\mathrm{AR}}$ ). For example, $\mathrm{OM}_{\mathrm{T}}$ in Fig. 6c (lower dashed line) becomes close to the $\mathrm{OM}_{\mathrm{T}}$ without $\mathrm{SO}_{2}$ in Fig. $3 \mathrm{a}$ (blue line). For major products contributing SOA mass, the reduc- tion of $\gamma_{\mathrm{in}, i}$ by one-third nearly approaches the $\gamma_{\mathrm{in}, i}$ estimated in pure water (upper boundary of $\mathrm{OM}_{\mathrm{AR}}$ ).

4. $k_{\mathrm{AC}, i}$ semi-empirically estimated using the set of model organic compounds (Sect. 3.4) can be limited in its expression of the reaction rates of various multifunctional organic products in the complex SOA system comprising a variety of organic compounds (Sect. 4.4). Figure 6d shows the sensitivity of the SOA model to variation of $k_{\mathrm{AC}, i}$ (increase/decrease by $100 \% / 50 \%)$.

5. $\mathrm{OM}_{\mathrm{AR}}$ is affected by OS formation due to the dynamic change in aerosol acidity (Sects. 3.5 and 4.3). In UNIPAR, the semi-empirical relationship used to predict OS formation was obtained using the data from toluene SOA internally mixed with sulfuric acid aerosol. However, both OS formation mechanisms and OS chemical stability are unclear. The prediction of OS formation needs to be revisited when more experimental data are available for various SOA systems.

6. Recent studies (Virtanen et al., 2010; Zelenyuk et al., 2010; Abramson et al., 2013) have reported that SOA viscosity increases due to the atmospheric aging process. In highly viscous aerosol, diffusion of a molecule could be significantly slow and affects various aerosol-phase reactions, including oligomerization, acid-catalyzed reactions and organosulfate formation. The effect of viscosity on rate constants was not counted in the kinetics of aerosol-phase reactions of the current UNIPAR model.

Among the model parameters, as shown in Fig. 6, vapor pressure and $\gamma_{i, j}$ would be the most influential on the predicted $\mathrm{OM}_{\mathrm{T}}$. Both vapor pressure and $\gamma_{i, j}$ span over eight orders of magnitude $\left(10^{-8}-10^{-2} \mathrm{~mm} \mathrm{Hg}\right.$ for vapor pressure and $10^{0}-10^{7}$ for $\gamma_{i, j}$ ). They are typically estimated using semiempirical equations based on the databases lacking in both diversity of compounds and experimental conditions. Inherent uncertainties in the SRR method and oxidation mechanisms within MCM can also affect the lumping structure, their concentration in multiphase, and the estimation of major thermodynamic parameters as described above.

In order to apply the UNIPAR model to the regionalscale air quality model, the model parameters need to be tested for various SOAs that originate from different anthropogenic and biogenic VOCs under ambient relevant conditions. The UNIPAR model of this study, which has been explored for the case of complete organic/electrolyte-phase separation, is applicable to less polar $\mathrm{SOA}(\mathrm{O}: \mathrm{C}$ ratio $\leq 0.62$ under ambient RH), including toluene SOA, 135-TMB, xylene SOA, alkene SOA, and terpene SOA. However, hydrophilic SOA such as isoprene SOA and benzene SOA can be mixable with electrolyte liquid phase and form a single phase. For these hydrophilic SOA, the model needs reconstruction for gas-particle partitioning (activity coefficients) 

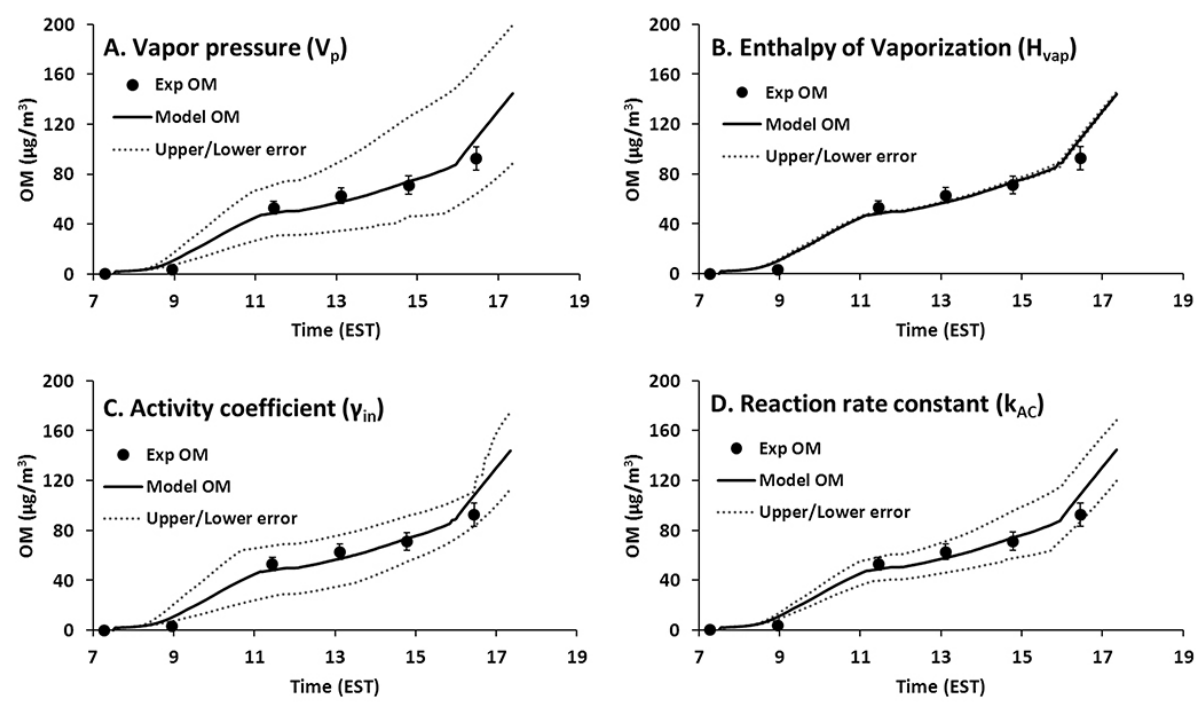

Fig. 6. Uncertainty of model prediction due to variation of major model parameters. Solid lines are for model prediction, symbols are for experimentally measured OM, and dashed lines are sensitivity test results (upper and lower cases within given variations of model parameters). The simulations employ the environmental condition of the experiment performed on 6 January 2012 with $190 \mathrm{ppb}$ of the initial toluene concentration (see Fig. 3a). (A) The estimated errors associated with vapor pressure $\left(V_{\mathrm{P}}\right)$ of lumping species were predicted with increasing/decreasing $V_{\mathrm{P}}$ by $100 \% / 50 \%$. (B) The estimated errors associated with enthalpy of vaporization $\left(H_{\text {vap }}\right)$ of lumping species were predicted with increasing/decreasing $H_{\text {vap }}$ by $10 \%$. (C) The estimated errors associated with activity coefficients $\left(\gamma_{\text {in }}\right)$ of lumping species in the inorganic phase were predicted with the $\gamma_{\text {in }}$ increased by 3 times (200\% increase) and decreased by one-third. (D) The estimated errors associated with reaction rate constants $\left(k_{\mathrm{AC}}\right)$ of lumping species in both the inorganic phase and organic phase were predicted with increasing/decreasing rate constants by $100 \% / 50 \%$.

of organic products in an organic/electrolyte single phase. In the future, the evolution of the lumping matrix of stoichiometric coefficients $\left(\alpha_{i, j}\right)$ via photochemical aging process is necessary to improve the prediction of SOA.

\section{Supplementary material related to this article is available online at http://www.atmos-chem-phys.net/14/ 4013/2014/acp-14-4013-2014-supplement.pdf.}

Acknowledgements. This work was supported by a grant from the National Science Foundation (ATM-0852747) and a Navy grant (N61331-11-1-G001).

Edited by: A. B. Guenther

\section{References}

Abramson, E., Imre, D., Beranek, J., Wilson, J., and Zelenyuk, A.: Experimental determination of chemical diffusion within secondary organic aerosol particles, Phys. Chem. Chem. Phys., 15, 2983-2991, 2013.

Alvarez, E. G., Viidanoja, J., Muoz, A., Writz, K., and Hjorth, J.: Experimental Confirmation of the Dicarbonyl Route in the Photo-oxidation of Toluene and Benzene, Environ. Sci. Technol., 41, 8362-8369, 2007.
Atkinson, R., Baulch, D. L., Cox, R. A., Crowley, J. N., Hampson Jr., R. F., and Kerr, J. A.: Summary of evaluated kinetic and photochemical data for atmospheric chemistry, IUPAC subcommittee on gas kinetic data evaluation for atmospheric chemistry web version, 1-56, 2001.

Baek, J., Hu, Y., Odman, M. T., and Russell, A. G.: Modeling secondary organic aerosol in CMAQ using multigenerational oxidation of semi-volatile organic compounds, J. Geophys. Res.Atmos., 116, D22204/1-D22204/12, 2011.

Barton, A. F. M.: CRC Handbook of Solubility Parameters and Other Cohesion Parameters, CRC Press. Inc., Boca Raton, 2nd Edn., 1991.

Bäumer, D., Vogel, B., Versick, S., Rinke, R., Möhler, O., and Schnaiter, M.: Relationship of visibility, aerosol optical thickness and aerosol size distribution in an ageing air mass over SouthWest Germany, Atmos. Environ., 42, 989-998, 2008.

Bertram, A. K., Martin, S. T., Hanna, S. J., Smith, M. L., Bodsworth, A., Chen, Q., Kuwata, M., Liu, A., You, Y., and Zorn, S. R.: Predicting the relative humidities of liquid-liquid phase separation, efflorescence, and deliquescence of mixed particles of ammonium sulfate, organic material, and water using the organic-to-sulfate mass ratio of the particle and the oxygen-tocarbon elemental ratio of the organic component, Atmos. Chem. Phys., 11, 10995-11006, doi:10.5194/acp-11-10995-2011, 2011.

Betterton, E. A. and Hoffmann, M. R.: Kinetics, mechanism, and thermodynamics of the reversible reaction of methylglyoxal with S(IV), J. Phys. Chem., 91, 3011-3020, 1987.

Bloss, C., Wagner, V., Jenkin, M. E., Volkamer, R., Bloss, W. J., Lee, J. D., Heard, D. E., Wirtz, K., Martin-Reviejo, M., Rea, 
G., Wenger, J. C., and Pilling, M. J.: Development of a detailed chemical mechanism (MCMv3.1) for the atmospheric oxidation of aromatic hydrocarbons, Atmos. Chem. Phys., 5, 641-664, doi:10.5194/acp-5-641-2005, 2005.

Cao, G. and Jang, M.: Effects of particle acidity and UV light on secondary organic aerosol formation from oxidation of aromatics in the absence of $\mathrm{NO}_{\mathrm{x}}$, Atmos. Environ., 41, 7603-7613, 2007.

Cao, G. and Jang, M.: An SOA Model for Toluene Oxidation in the presence of Inorganic Aerosols, Environ. Sci. Technol., 44, 727-733, 2010.

Cappa, C. D. and Wilson, K. R.: Multi-generation gas-phase oxidation, equilibrium partitioning, and the formation and evolution of secondary organic aerosol, Atmos. Chem. Phys., 12, 9505-9528, doi:10.5194/acp-12-9505-2012, 2012

Carlton, A. G., Turpin, B. J., Altieri, K. E., Seitzinger, S. P., Mathur, R., Roselle, S. J., and Weber, R. J.: CMAQ Model Performance Enhanced When In-Cloud Secondary Organic Aerosol is Included: Comparisons of Organic Carbon Predictions with Measurements, Environ. Sci. Technol., 42, 8798-8802, 2008.

Chang, E. I. and Pankow, J. F.: Prediction of activity coefficients inliquid aerosol particles containing organic compounds, dissolved inorganic salts, and water Part 2: Consideration of phase separation effects by an X-UNIFAC model, Atmos. Environ., 40, 6422-6436, 2006.

Ciobanu, V. G., Marcolli, C., Krieger, U. K., Weers, U., and Peter, T.: Liquid-Liquid Phase Separation in Mixed Organic/Inorganic Aerosol Particles, J. Phys. Chem. A, 113, 10966-10978, 2009.

Clegg, S. L., Seinfeld, J. H., and Brimblecombe, P.: Thermodynamic modelling of aqueous aerosols containing electrolytes and dissolved organic compounds, J. Aerosol. Sci., 32, 713-738, 2001.

Czoschke, N. M. and Jang, M.: Acidity effects on the formation of $\alpha$-pinene ozone SOA in the presence of inorganic seed, Atmos. Environ., 40, 4370-4380, 2006.

Czoschke, N. M., Jang, M., and Kamens, R. M.: Effect of acidic seed on biogenic secondary organic aerosol growth, Atmos. Environ., 37, 4287-4299, 2003.

Darer, A. I., Cole-Filipiak, N. C., O'Connor, A. E., and Elrod, M. J.: Formation and stability of atmospherically relevant isoprenederived organosulfates and organonitrates, Environ. Sci. Technol., 45, 1895-1902, 2011.

Donahue, N. M., Robinson, A. L., and Pandis, S.: Coupled partitioning, dilution, and chemical aging of semivolatile organics, Environ. Sci. Technol., 40, 2635-2643, 2006.

Ervens, B., Turpin, B. J., and Weber, R. J.: Secondary organic aerosol formation in cloud droplets and aqueous particles (aqSOA): a review of laboratory, field and model studies, Atmos. Chem. Phys., 11, 11069-11102, doi:10.5194/acp-1111069-2011, 2011.

Galloway, M. M., Chhabra, P. S., Chan, A. W. H., Surratt, J. D., Flagan, R. C., Seinfeld, J. H., and Keutsch, F. N.: Glyoxal uptake on ammonium sulphate seed aerosol: reaction products and reversibility of uptake under dark and irradiated conditions, Atmos. Chem. Phys., 9, 3331-3345, doi:10.5194/acp-9-3331-2009, 2009.

Garland, R. M., Elrod, M. J., Kincaid, K., Beaver, M. R., Jimenez, J. L., and Tolbert, M. A.: Acid-catalyzed reactions of hexanal on sulfuric acid particles: Identification of reaction products, Atmos. Environ, 40, 6863-6878, 2006.
Gopinathan, N. and Saraf, D. N.: Predict heat of vaporization of crudes and pure components Revised II, Fluid Phase Equilibr., 179, 277-284, 2001.

Iinuma, Y., Boge, O., Gnauk, T., and Hermann, H.: Aerosolchamber study of the $\alpha$-pinene $/ \mathrm{O}_{3}$ reaction: influence of particle acidityon aerosol yields and products, Atmos. Environ., 38, 761-773, 2004.

Iinuma, Y., Boge, O., Kahnt, A., and Hermann, H.: Laboratory chamber studies on the formation of organosulfates from reactive uptake of monoterpene oxides, Phys. Chem. Chem. Phys., 11, 7985-7997, 2009

IPCC: Intergovernmental Panel on Climate Change (IPCC): Climate change: The scientific basis, Cambridge University Press, Cambridge, 2001

Izumi, K. and Fukuyama, T.: Photochemical aerosol formation from aromatic hydrocarbons in the presence of $\mathrm{NO}_{\mathrm{x}}$, Atmos. Environ., 24, 1433-1490, 1990

Jang, M. and Kamens, R. M.: A Thermodynamic Approach for Modeling Partitioning of Semivolatile Organic Compounds on Atmospheric Particulate Matter: Humidity Effects, Environ. Sci. Technol., 32, 1237-1243, 1998.

Jang, M. and Kamens, R. M.: Atmospheric Secondary Aerosol Formation by Heterogeneous Reactions of Aldehydes in the Presence of a Sulfuric Acid Aerosol Catalyst, Environ. Sci. Technol., 35, 4758-4766, 2001

Jang, M., Carroll, B., Chandramouli, B., and Kamens, R. M.: Particle growth by acid-catalyzed heterogeneous reactions of organic carbonyls on preexisting aerosols, Environ. Sci. Technol., 37, 3828-3837, 2003

Jang, M., Czoschke, N. M., Northcross, A. L., Cao, G., and Shaof, D.: SOA Formation from Partitioning and Heterogeneous Reactions: Model Study in the Presence of Inorganic Species, Environ. Sci. Technol., 40, 3013-3022, 2006.

Jang, M., Cao, G., and P., J.: Acidity Measurement of Atmospheric Aerosol by a Colorimetric Analysis, Aerosol Sci. Tech., 42, 409420, 2008.

Jeffries, H. E., Gary, M. W., Kessler, M., and Sexton, K. G.: Morphecule reaction mechanism, MORPHO, ALLOMORPHIC simulation software, 1998

Jenkin, M. E., Saunders, S. M., and Pilling, M. J.: The tropospheric degradation of volatile organic compounds: a protocol for mechanism development, Atmos. Environ., 31, 81-104, 1997.

Jenkin, M. E., Saunders, S. M., Wagner, V., and Pilling, M. J.: Protocol for the development of the Master Chemical Mechanism, MCM v3 (Part B): tropospheric degradation of aromatic volatile organic compounds, Atmos. Chem. Phys., 3, 181-193, doi:10.5194/acp-3-181-2003, 2003.

Johnson, D., Jenkin, M. E., Wirtz, K., and Martin-Reviejo, M.: Simulating the Formation of Secondary Organic Aerosol from the Photooxidation of Toluene, Environ. Chem., 1, 150-165, 2004.

Kamens, R., Jang, M., Chien, C. J., and Leach, K.: Aerosol formation from the reaction of a-pinene and ozone using a gas-phase kinetics-aerosol partitioning model, Environ. Sci. Technol., 33, 1430-1438, 1999.

Kleindienst, T. E., Edney, E. O., Lewandowski, M., Offenberg, J. H., and Jaoui, M.: Secondary organic carbon and aerosol yields from the irradiations of isoprene and $\alpha$-pinene in the presenceof $\mathrm{NO}_{\mathrm{x}}$ andSO $\mathrm{S}_{2}$, Environ. Sci. Technol., 40, 3807-3812, 2006. 
Kleindienst, T. E., Jaoui, M., Lewandowski, M., Offenberg, J. H., Lewis, C. W., Bhave, P. V., and Edney, E. O.: Estimates of the contributions of biogenic and anthropogenic hydrocarbons to secondary organic aerosol at a southeastern US location., Atmos. Environ., 41, 8288-8300, 2007.

Kleinman, L. I., Springston, S. R., Daum, P. H., Lee, Y.-N., Nunnermacker, L. J., Senum, G. I., Wang, J., Weinstein-Lloyd, J., Alexander, M. L., Hubbe, J., Ortega, J., Canagaratna, M. R., and Jayne, J.: The time evolution of aerosol composition over the Mexico City plateau, Atmos. Chem. Phys., 8, 1559-1575, doi:10.5194/acp-8-1559-2008, 2008.

Kolska, Z., Ruzicka, V., and Gani, R.: Estimation of the Enthalpy of Vaporization and the Entropy of Vaporization for Pure Organic Compounds at $298.15 \mathrm{~K}$ and at Normal Boiling Temperature by a Group Contribution Method, Ind. Eng. Chem. Res., 44, 84368454, 2005.

Kroll, J., Chan, A. W. H., Ng, N. L., Flagan, R. C., , and Seinfeld, J. H.: Reactions of semivolatile organics and their effects on secondary organic aerosol formation, Environ. Sci. Technol., 41, 3545-3550, 2007.

$\mathrm{Ku}, \mathrm{H} .:$ Notes on the Use of Propagation of Error Formulas, J. Res. Nbs C. Eng. Inst., 70, 263-273, 1966.

Kuwata, M., Shao, W., Lebouteiller, R., and Martin, S. T.: Classifying organic materials by oxygen-to-carbon elemental ratio to predict the activation regime of Cloud Condensation Nuclei (CCN), Atmos. Chem. Phys., 13, 5309-5324, doi:10.5194/acp-13-53092013, 2013.

Kwok, E. S. C. and Atkinson, R.: Estimation of hydroxyl radical reaction rate constants for gas phase organic compounds using a structure reactivity relationship: an update, Atmos. Environ., 29, 1685-1695, 1995.

Lal, V., Khalizov, A. F., Lin, Y., Galvan, M. D., Connell, B. T., and Zhang, R.: Hetorogeneous Reactions of Epoxides in Acidic Media, J. Phys. Chem. A, 116, 6078-6090, 2012.

Li, J. and Jang, M.: Kinetic study of esterification of sulfuric acid with alcohols in aerosol bulk phase, Atmos. Chem. Phys. Discuss., 13, 23217-23250, doi:10.5194/acpd-13-23217-2013, 2013.

Liggio, J., Li, S.-M., and Mclaren, R.: Heterogeneous Reaction of Glyoxal on Particulate Matter: Identification of Acetals and Sulfate Esters, Environ. Sci. Technol., 39, 1532-1541, 2005.

Loza, C. L., Chhabra, P. S., Yee, L. D., Craven, J. S., Flagan, R. C., and Seinfeld, J. H.: Chemical aging of $m$-xylene secondary organic aerosol: laboratory chamber study, Atmos. Chem. Phys. Discuss., 11, 24969-25010, doi:10.5194/acpd-11-24969-2011, 2011.

Metzger, A., Dommen, J., Gaeggeler, K., Duplissy, J., Prevot, A. S. H., Kleffmann, J., Elshorbany, Y., Wisthaler, A., and Baltensperger, U.: Evaluation of 1,3,5 trimethylbenzene degradation in the detailed tropospheric chemistry mechanism, MCMv3.1, using environmental chamber data, Atmos. Chem. Phys. Discuss., 8, 11567-11607, doi:10.5194/acpd-8-11567-2008, 2008.

Morris, R. E., Koo, B., Guenther, A., Yarwood, G., McNally, D., Tesche, T. W., Tonnesen, G., Boylan, J., and Brewer, P.: Model sensitivity evaluation for organic carbon using two multipollutant air quality models that simulate regional haze in the southeastern United States., Atmos. Environ., 40, 4960-4972, 2006.
Myrdal, P. and Yalkowsky, S.: Estimating pure component vapor pressures of complex organic molecules, Ind. Eng. Chem. Res., 36, 2494-2499, 1997.

Nakao, S., Clark, C., Tang, P., Sato, K., and Cocker III, D.: Secondary organic aerosol formation from phenolic compounds in the absence of $\mathrm{NO}_{\mathrm{x}}$, Atmos. Chem. Phys., 11, 10649-10660, doi:10.5194/acp-11-10649-2011, 2011.

Ng, N. L., Kroll, J. H., Chan, A. W. H., Chhabra, P. S., Flagan, R. C., and Seinfeld, J. H.: Secondary organic aerosol formation from $m$-xylene, toluene, and benzene, Atmos. Chem. Phys., 7, 3909-3922, doi:10.5194/acp-7-3909-2007, 2007.

Öberg, T.: A general structure-property relationship to predict the enthalpy of vaporisation at ambient temperatures, SAR and QSAR, Environ. Res., 18, 127-139.

Odian, G.: Priciples of Polymerization, John Wiley \& Sons, New York, 2nd Edn., 1981.

Odum, J. R., Hoffmann, T., Bowman, F. A., Collins, D., Flagan, R. C., and Seinfeld, J. H.: Gas/particle partitioning and secondary organic aerosol yields, Environ. Sci. Technol., 30, 2580, doi:10.1021/es950943+, 1996.

Olson, C. N., Galloway, M. M., Yu, G., Hedman, C. J., Lockett, M. R., Yoon, T., Stone, E. A., Smith, L. M., and Keutsch, F. N.: Hydroxycarboxylic acid-derived organosulfates: Synthesis, stability, and quantification in ambient aerosol, Environ. Sci. Technol., 45, 6468-6474, 2011.

Pankow, J.: absorption model of gas/particle partitioning of organic compounds in the atmosphere, Atmos. Environ., 28, 185-188, 1994.

Peltier, R. E., Sullivan, A. P., Weber, R. J., Wollny, A. G., Holloway, J. S., Brock, C. A., Gouw, J. A. D., and Atlas, E. L.: No evidence for acid-catalyzed secondary organic aerosol formation in power plant plumes over metropolitan Atlanta, Georgia, Geophys Res. Lett., 34, L06801, doi:10.1029/2006GL028780, 2007.

Press, W. H., Teukolsky, S. A., Vetterling, W. T., and Flannery, B. P.: Numirical Recipes in Fortran 77, Cambridge Univ. Press, New York, 2nd Edn.., 1992.

Rickard, A. R., Wyche, K. P., A., M., Monks, P. S., Ellis, A. M., Dommen, J., Baltensperger, U., Jenkind, M. E., and Pillinge, M. J.: Gas phase precursors to anthropogenic secondary organic aerosol: Using the Master Chemical Mechanism to probe detailed observations of 1,3,5-trimethylbenzene photo-oxidation, Atmos. Environ., 44, 5423-5433, 2010.

Sato, K., Hatakeyama, S., and Imamura, T.: Secondary organic aerosol formation during the photooxidation of toluene: $\mathrm{NO}_{\mathrm{x}}$ dependence of chemical composition, J. Phys. Chem. A, 111, 9796-9808, 2007.

Sato, K., Takami, A., Kato, Y., Seta, T., Fujitani, Y., Hikida, T., Shimono, A., and Imamura, T.: AMS and LC/MS analyses of SOA from the photooxidation of benzene and 1,3,5-trimethylbenzene in the presence of $\mathrm{NO}_{\mathrm{x}}$ : effects of chemical structure on SOA aging, Atmos. Chem. Phys., 12, 4667-4682, doi:10.5194/acp-124667-2012, 2012.

Schell, B., Ackermann, I. J., Hass, H., Binkowski, F. S., and Ebel, A.: Modeling the formation of secondary organic aerosol within a comprehensive air quality model system, J. Geophys. Res., 106, 28275-28293, 2001.

Schwartz, J., Dockery, D. W., and Neas, L. M.: Is daily mortality associated specifically with fine particles, JAPCA J. Air Waste Ma., 46, 927-939, 1996. 
Simon, H. and Bhave, P. V.: Simulating the Degree of Oxidation in Atmospheric Organic Particles, Environ. Sci. Technol., 46, 331339, 2012.

Simpson, D., Yttri, K. E., Klimont, Z., Kupiainen, K., Caseiro, A., Gelencser, A., Pio, C., Puxbaum, H., and Legrand, M.: Modeling carbonaceous aerosol over Europe: analysis of CARBOSOL and EMEP EC/OC campaigns, J. Geophy. Res., 112, D23S14, doi:10.1029/2006JD008158, 2007.

Smith, D. F., Kleindienst, T. E., and McIver, C. D.: Primary Product Distributions from the Reaction of $\mathrm{OH}$ with $m-, p$-Xylene, 1,2,4- and 1,3,5-Trimethylbenzene, J. Atmos. Chem., 34, 339364, 1999.

Song, M., Marcolli, C., Krieger, U. K., Zuend, A., and Peter, T.: Liquid-liquid phase separation and morphology of internally mixed dicarboxylic acids/ammonium sulfate/water particles, Atmos. Chem. Phys., 12, 2691-2712, doi:10.5194/acp-12-26912012, 2012.

Surratt, J. D., Lewandowski, M., Offenberg, J. H., Jaoui, M., Kleindienst, T. E., Edney, E. O., and Seinfeld, J. H.: Effect of acidity on secondary organic aerosol formation from isoprene., Environ. Sci. Technol., 41, 5363-5369, 2007.

Virtanen, A., Joutsensaari, J., Koop, T., Kannosto, J., Yli-Pirila, P., Leskinen, J., Mäkelä, J. M., Holopainen, J. K., Pöschl, U., Kulmala, M., Worsnop, D. R., and Laaksonen, A.: An amorphous solid state of biogenic secondary organic aerosol particles, Nature, 467, 824-827, 2010.

Wagner, V., Jenkin, M. E., Saunders, S. M., Stanton, J., Wirtz, K, and Pilling, M. J.: Modelling of the photooxidation of toluene: conceptual ideas for validating detailed mechanisms, Atmos. Chem. Phys., 3, 89-106, doi:10.5194/acp-3-89-2003, 2003.
Wyche, K. P., Monks, P. S., Ellis, A. M., Cordell, R. L., Parker, A. E., Whyte, C., Metzger, A., Dommen, J., Duplissy, J., Prevot, A. S. H., Baltensperger, U., Rickard, A. R., and Wulfert, F.: Gas phase precursors to anthropogenic secondary organic aerosol: detailed observations of 1,3,5-trimethylbenzene photooxidation, Atmos. Chem. Phys., 9, 635-665, doi:10.5194/acp-9-635-2009, 2009.

Zelenyuk, A., Ezell, M. J., Perraud, V., Johnson, S. N., Bruns, E. A., Yu, Y., Imre, D., Alexander, M. L., and Finlayson-Pitts, B. J.: Characterization of organic coatings on hygroscopic salt particles and their atmospheric impacts, Atmos. Environ., 44, 1209-1218, 2010.

Zhang, Q., Jimenez, J. L., Worsnop, D. R., and Canagaratna, M. R.: A Case study of urban particle acidity and its effect on secondary organic aerosol, Environ. Sci. Technol., 41, 3213-3219, doi:10.1021/es061812j, 2007.

Zhao, L., Ni, N., and Yalkowsky, S. H.: A modification of Trouton's rule by simple molecular parameters for hydrocarbon compounds, Ind. Eng. Chem. Res., 38, 324-327, 1999.

Zuend, A. and Seinfeld, J. H.: Modeling the gas-particle partitioning of secondary organic aerosol: the importance of liquidliquid phase separation, Atmos. Chem. Phys., 12, 3857-3882, doi:10.5194/acp-12-3857-2012, 2012.

Zuend, A., Marcolli, C., Booth, A. M., Lienhard, D. M., Soonsin, V., Krieger, U. K., Topping, D. O., McFiggans, G., Peter, T., and Seinfeld, J. H.: New and extended parameterization of the thermodynamic model AIOMFAC: calculation of activity coefficients for organic-inorganic mixtures containing carboxyl, hydroxyl, carbonyl, ether, ester, alkenyl, alkyl, and aromatic functional groups, Atmos. Chem. Phys., 11, 9155-9206, doi:10.5194/acp11-9155-2011, 2011. 